\title{
The in vivo impact of MsLAC1, a Miscanthus laccase isoform, on lignification and lignin composition contrasts with its in vitro substrate preference
}

Feng He${ }^{1}$, Katja Machemer-Noonan ${ }^{1}$, Philippe Golfier ${ }^{1}$, Faride Unda ${ }^{2}$, Johanna Dechert ${ }^{1}$, Wan Zhang ${ }^{1}$, Natalie Hoffmann ${ }^{3}$, Lacey Samuels ${ }^{3}$, Shawn D. Mansfield ${ }^{2}$, Thomas Rausch ${ }^{1 *}$ and Sebastian Wolf ${ }^{*}$ (D)

\begin{abstract}
Background: Understanding lignin biosynthesis and composition is of central importance for sustainable bioenergy and biomaterials production. Species of the genus Miscanthus have emerged as promising bioenergy crop due to their rapid growth and modest nutrient requirements. However, lignin polymerization in Miscanthus is poorly understood. It was previously shown that plant laccases are phenol oxidases that have multiple functions in plant, one of which is the polymerization of monolignols. Herein, we link a newly discovered Miscanthus laccase, MsLAC1, to cell wall lignification. Characterization of recombinant MsLAC1 and Arabidopsis transgenic plants expressing MsLAC1 were carried out to understand the function of MsLAC1 both in vitro and in vivo.

Results: Using a comprehensive suite of molecular, biochemical and histochemical analyses, we show that MsLAC1 localizes to cell walls and identify Miscanthus transcription factors capable of regulating MsLAC1 expression. In addition, MSLAC1 complements the Arabidopsis lac4-2 lac17 mutant and recombinant MSLAC1 is able to oxidize monolignol in vitro. Transgenic Arabidopsis plants over-expressing MsLAC1 show higher G-lignin content, although recombinant MsLAC1 seemed to prefer sinapyl alcohol as substrate.

Conclusions: In summary, our results suggest that MSLAC1 is regulated by secondary cell wall MYB transcription factors and is involved in lignification of xylem fibers. This report identifies MsLAC1 as a promising breeding target in Miscanthus for biofuel and biomaterial applications.
\end{abstract}

Keywords: Miscanthus, Arabidopsis, Laccase, Lignin, S/G ratio, Interfascicular fibers, Lignocellulosic biomass

\section{Background}

Miscanthus, a perennial C4 grass, has been promoted as a promising energy crop due to its high biomass yield and low demand for fertilizer and pesticides [1]. Compared to other species, Miscanthus biomass contains significantly less moisture and produces less ash, making it suitable for biofuel generation and production of valuable chemicals via bio-conversion processes [2]. However, current Miscanthus biomass utilization for biofuel production is largely limited by cell wall recalcitrance

\footnotetext{
* Correspondence: thomas.rausch@cos.uni-heidelberg.de;

sebastian.wolf@cos.uni-heidelberg.de

${ }^{1}$ Centre for Organismal Studies (COS) Heidelberg, Heidelberg University,

Heidelberg, Germany

Full list of author information is available at the end of the article
}

towards biochemical conversion, to which lignin content and quality contributes significantly. In addition, lignin decreases digestibility when Miscanthus biomass is used as feed [3]. Consequently, lignin content and quality as well as the cellulose-to-lignin ratio have a substantial impact on the utilization and degradability of Miscanthus biomass $[3,4]$. Therefore, a deeper understanding of factors controlling lignin biosynthesis and deposition in Miscanthus is required for improving the utility of this abundant source of lignocellulosic biomass.

Lignin is one of the major components of plant secondary cell walls and is mainly composed of the polymerized monolignols $p$-coumaryl alcohol, coniferyl alcohol, and sinapyl alcohol, resulting in $\mathrm{H}, \mathrm{G}$, and $\mathrm{S}$ 
lignin, respectively. Lignin biosynthesis includes three major steps: monolignol biosynthesis in the cytosol, transport of monolignols to the cell wall matrix, and polymerization into the heterogeneous, cross-linked lignin polymer [5]. While recent studies in Arabidopsis have identified and characterized a large number of enzymes and transcription factors responsible for these steps, and each can significantly affect lignin content and composition [6], knowledge about lignification in Miscanthus remains thus far limited. However, a recently completed transcriptome analysis, based on developing internodes of Miscanthus lutarioriparius, a Miscanthus transcriptome database [7], and Miscanthus sinensis draft genome (Miscanthus sinensis v7.1 DOEJGI, http://phytozome.jgi.doe.gov/), revealed many similarities to other species concerning the secondary cell wall biosynthetic machinery [8]. Furthermore, the transcription factor MsSND1 was shown to be able to regulate secondary cell wall formation, including lignification, similar to its orthologue AtSND1 in Arabidopsis [9]. These results and previous studies in other monocots indicate a partially conserved secondary cell wall biosynthetic pathway between monocot and dicot plants [10-13]; allowing the study of potential lignification-related genes of Miscanthus by exploiting existing knowledge from Arabidopsis and other plant species.

Following biosynthesis, monolignols are oxidized by peroxidases and/or laccases to monolignol radicals, which spontaneously polymerize in the cell wall.. There is strong experimental support for peroxide-dependent peroxidases [14] and oxygen-dependent laccases in the polymerization process [15-18]. In Arabidopsis, laccase isoforms involved in lignification appear to have redundant functions [19]. Specifically, the Arabidopsis lac4 or lac17 single mutants result in only slightly reduced lignin content, whereas the lac4-2 lac17 double mutant displays up to $40 \%$ less lignin in the stem [15]. Furthermore, the lac4 lac11 lac17 triple mutant is characterized by vascular bundles almost entirely devoid of lignin [19]. Although attempts have been made to identify the physiological role of different laccase isoforms $[18,20]$, it remains difficult to assign specific functions to individual laccases due to redundancy and broad substrate specificities [16].

In this study, a Miscanthus laccase isoform closely related to AtLAC17 was cloned and named MsLAC1. $M S L A C 1$ transcripts were expressed primarily in elongating internodes, sharing an expression pattern with other secondary cell wall-related genes. Further experiments revealed that the promoter of the MsLAC1 gene is targeted by MsSCM4, a putative orthologue of the Arabidopsis secondary wall synthesis regulators AtMYB58/63 [9]. MsLAC1 protein is secreted into the cell wall and the recombinant MsLAC1 protein is able to catalyze oxidation of monolignols. MsLAC1 also functionally complements the Arabidopsis lac4-2 lac17 double mutant, and upon ectopic expression impacts lignification, both in quantity and quality, with an increased S/G ratio.

\section{Results \\ Identification of laccase sequences in a Miscanthus sinensis transcriptome}

Using published laccase nucleotide sequences from Arabidopsis, Sorghum, and Brachypodium, we performed tBLASTn analysis of a Miscanthus transcriptome [7]. In total, 95 laccase-like contigs were identified, 28 of them containing complete sequences for putative laccase open reading frames (ORFs). Previous studies in Arabidopsis suggested a division of the laccase family into six subgroups [21], but fewer subgroups have been described for monocot species. For example, in Brachypodium, phylogenetic analysis revealed four subgroups [22], while sugarcane contains five subgroups [16]. Compared to dicot species, laccase families in monocots appear to be larger $[16,22]$. A phylogenetic analysis was performed to classify laccase contigs found in the Miscanthus EST database [7] against Arabidopsis and Brachypodium laccases, respectively (Fig. 1 and Additional file 1: Figure S1).

This analysis identified Mxg_TContig47643 (Fig. 1) as an ORF related to AtLAC17, which is known to be involved in lignification [15]. We cloned a laccase coding sequence, which we named MsLAC1, using primers based on Mxg TContig47643 from a of Miscanthus sinensis cDNA preparation. At the protein level, the sequence identities of MsLAC1 were 96 and 68\%, compared to Mxg_TContig47643 and AtLAC17, respectively, indicating that MsLAC1 was derived from a gene not identical but closely related to Mxg TContig47643. To inspect the relationship between MsLAC1 and other laccases that were previously reported to be involved in lignification, a multiple sequence alignment was carried out with characterized laccase proteins (Fig. 1b, Additional file 1: Figure S2), including those from Brachypodium distachyon (BdLAC5, [23]), sugarcane (SofLAC, [16]), poplar (PtLAC3, [17]), and Arabidopsis thaliana (AtLAC4 and AtLAC17, [15]). AtLAC17, which affects the deposition of guaiacyl (G) lignin in the interfascicular fibers [15], showed the highest sequence similarity to MsLAC1 (77\%). MsLAC1 contains four conserved copper-binding sites and a predicted $\mathrm{N}$-terminal signal peptide for secretion (Additional file 1: Figure S2). The predicted molecular weight and isoelectric point of non-glycosylated MsLAC1 are $63.0 \mathrm{kDa}$ and 5.95, respectively. However, since the MsLAC1 protein sequence contains more than 15 putative $\mathrm{N}$ glycosylation sites, the mature protein was expected to be considerably larger [24]. 


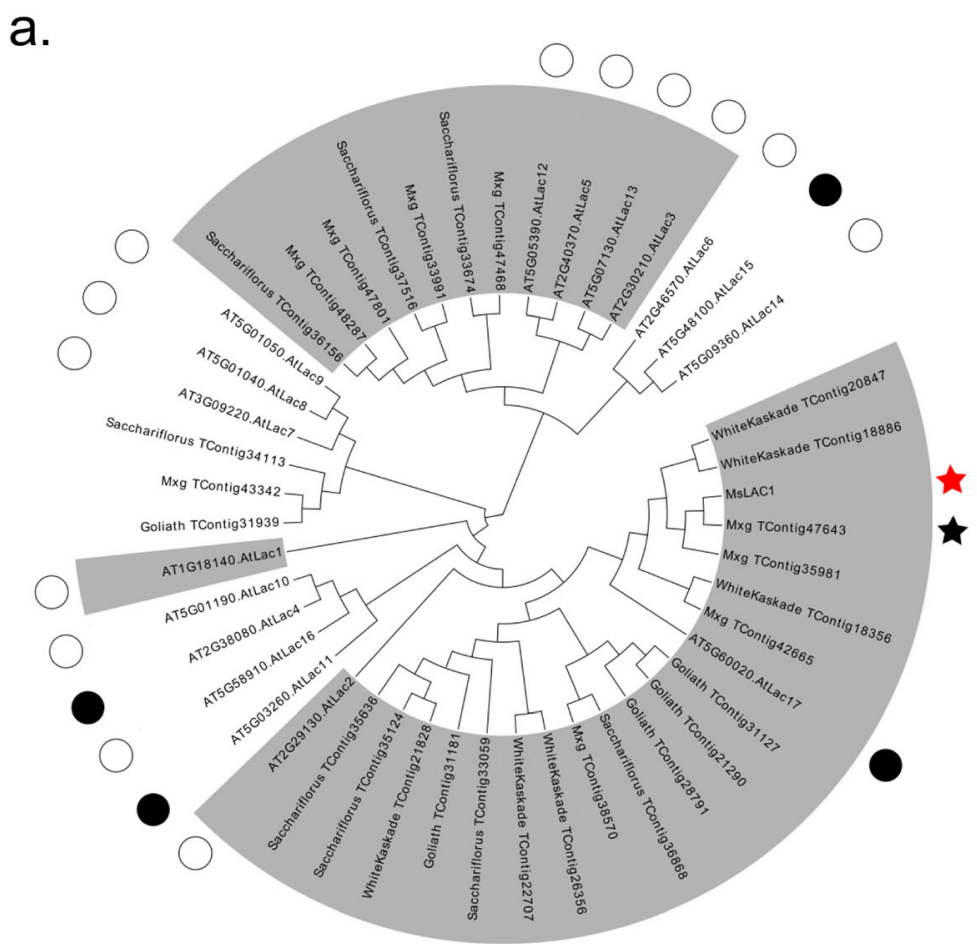

b.

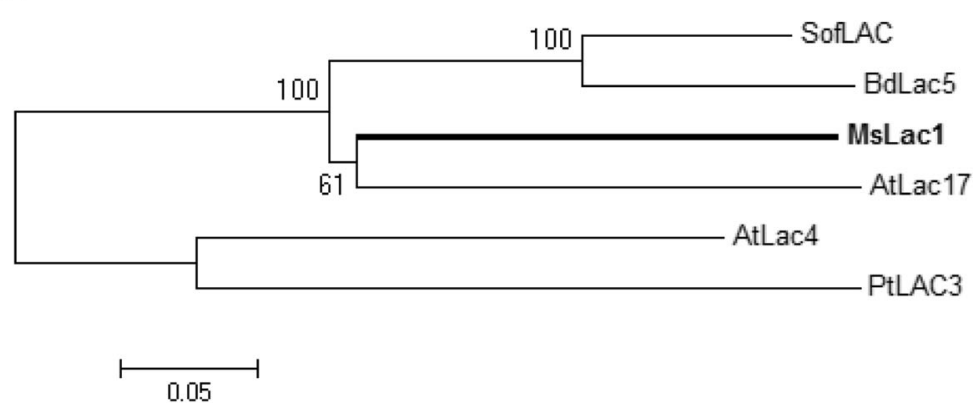

Fig. 1 Phylogenetic analysis of laccase sequences from different plant species. Alignments were conducted with Mega 5 using the Neighborjoining method. a All available Miscanthus laccase sequences from different species (e.g. goliath, saccharifolius) and Arabidopsis laccases (marked by circle) were included. Black circles indicate Arabidopsis laccases involved in lignin biosynthesis. Different laccase subgroups were categorized based on the results of (Turlapati et al., 2011) and marked with grey background. Mxg TContig47643 (black star), which clustered in subgroup 1 together with AtLAC17, was used for primer design to amplify the open reading frame of MSLAC1 (red star). Note that MsLAC1 is closely related to, but not identical with the open reading frame of Mxg_TContig47643 (95\% sequence identity at protein level). b Sequences of Miscanthus (MsLAC1), Brachypodium (BdLAC5), Saccharum (SofLAC), Populus (PtLAC3) and Arabidopsis (AtLAC4 and AtLAC17) laccases were included

MsLAC1 is preferentially expressed in lignifying tissues, including young internodes and leaf sheaths and is coexpressed with other lignification genes

To explore whether MsLAC1 is involved in the lignification process, the relative expression levels of MSLAC1 were first determined by GPCR in different organs (leaf, stem, and root) in plants of increasing age (10 days, 1 month, 2 months and 3 months; Fig. 2a). While MsLAC1 transcripts were detected in all organs, the highest expression was detected in the stem, which is typically highly lignified. In general, the expression of MsLAC1 decreased with increasing plant age. Since the process of lignification starts early during tissue maturation, MsLAC1 transcripts were subsequently monitored along developmental gradients of stem and leaf, respectively. Specifically, seven shoot internodes as well as five leaf sections from 6-month-old, mature plants were analyzed for MsLAC1 expression (Fig. 2b). In agreement with [22], the highest expression was detected in the youngest tissues, i.e., the leaf sheath (including the growing zone) and the youngest shoot internode, while gene expression was significantly lower in mature tissues.

To compare the expression of MsLAC1 with genes predicted to be involved in lignification, co-expression 
a.
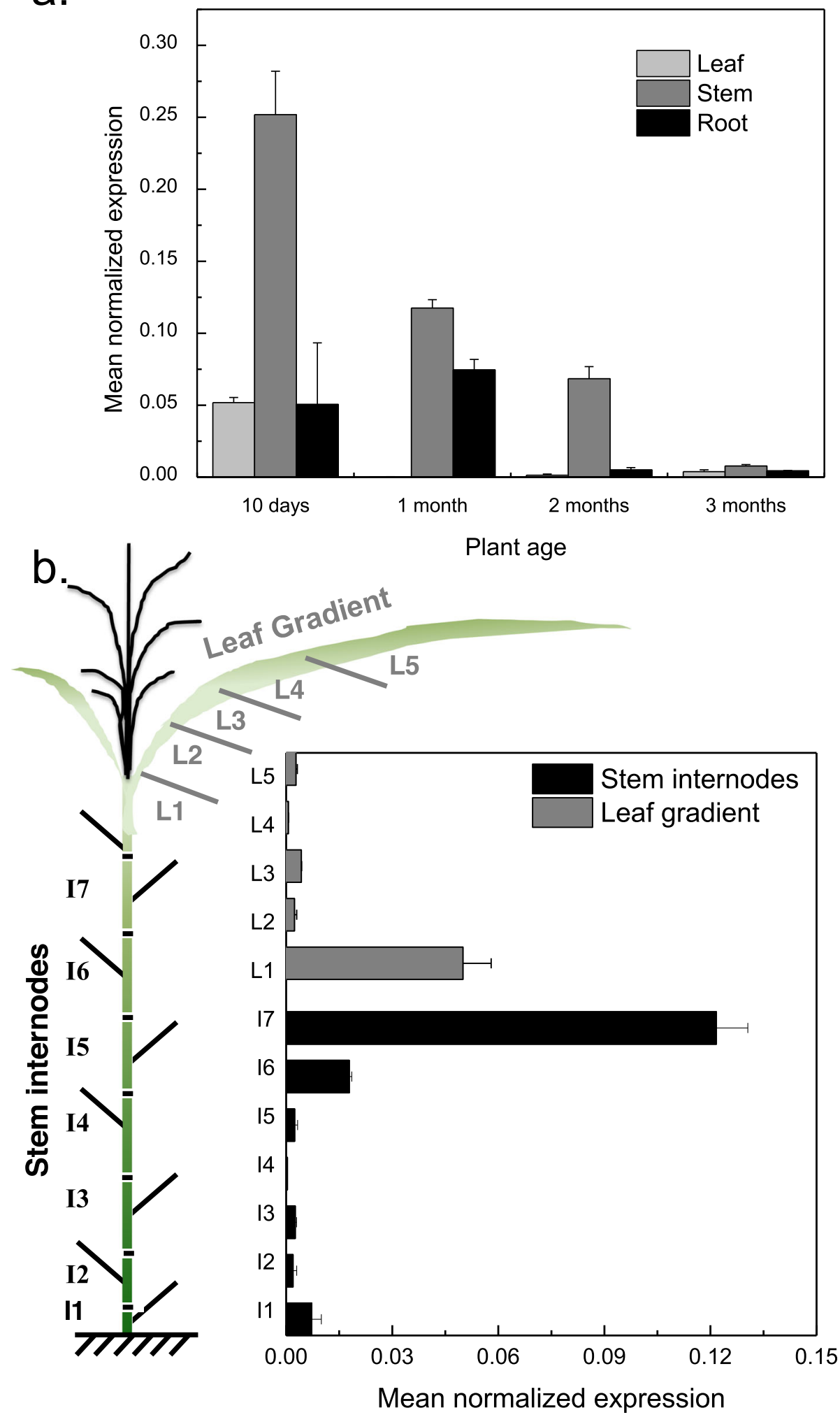

Plant age

Fig. 2 Expression pattern of MSLAC1 as quantified by qPCR. Expression pattern in a different tissues of different plant age and $\mathbf{b}$ stem internodes and leaf gradient of mature, 6-month-old Miscanthus plants. The cartoon in $\mathbf{b}$ displays the sampling mode. Transcript levels were determined by GPCR and normalized with respect to PP2A expression 
analysis was performed. Expression of putative cell wallrelated transcription factors $M s S N D 1, M s S C M 2$, 3, and 4 , and two likely orthologues of genes involved in lignin biosynthesis, MsCCoAOMT and MsHCT, were compared with MsLAC1 gene expression along the Miscanthus plant development gradients [9, 25]. Generally, all selected genes displayed higher expression levels in the stem as compared to the leaf (Fig. 3a). Along the leaf gradient, highest expression of the majority of genes was observed in the first section (i.e., including the sheath) of the leaf (or second for MsHCT), and expression levels decreased sharply in more mature leaf sections (Fig. 3a; b). For all analyzed genes, highest expression in the stem was detected in the three youngest internodes, strongly declining in older internodes, in agreement with lignin staining patterns (Fig. 3c). Together, these results are consistent with the hypothesis that MsLAC1 is involved in the lignification process.

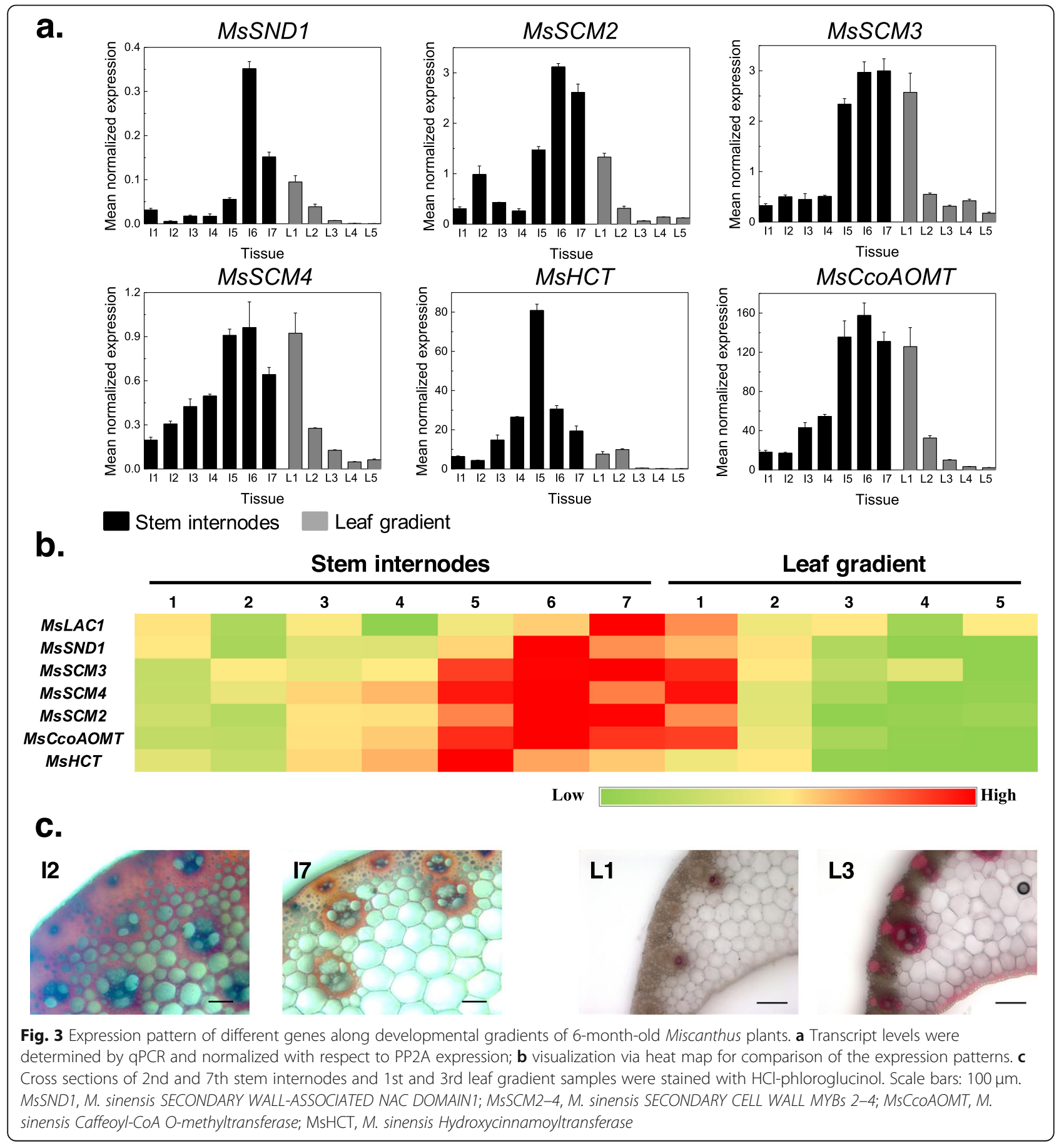


The promoter of the MsLac1 gene is activated by transcription factors regulating lignin biosynthesis The newly identified sequence of MsLAC1 was used to query the regulatory $5^{\prime}$-upstream region in a partially assembled genome sequence database of Miscanthus sinensis. A region comprising $1539 \mathrm{bp}$ upstream of the MsLAC1 start codon was isolated from genomic DNA. This putative promoter sequence was first analyzed for possible transcription factor (TF) binding sites, using the Genomatix MatInspector software, using a core similarity of $>0.85$ [26]. Secondary cell wall NAC binding elements (SNBEs) and secondary wall MYB responsive elements (SMREs) are important cis-elements involved in the regulation of secondary wall biosynthesis by associated NAC and MYB factors [27]. Using the MatInspector software, a total of 16 putative regulatory sites were identified in the proposed regulatory region, including three SNBEs and two SMREs. The regulation of cell wall lignification is controlled via a complex network, including a number of well-characterized transcription factors, e.g. MYB factors [28]. To establish the corresponding network for Miscanthus, we had previously cloned MsSND1, MsVND7, MsSCM2, 3, 4, and MsMYB52 as putative orthologues of the Arabidopsis secondary wall synthesis regulators AtSND1, AtVND7, AtMYB85, AtMYB43, AtMYB58/63 and AtMYB52, respectively [9, 29]. We tested the ability of these Miscanthus TFs to regulate $M S L A C 1$ expression by quantifying the activity of a luciferase reporter driven by the MsLAC1 promoter after co-bombardment into grapevine suspensioncultured cells (Fig. 4a). The results demonstrate that pMsLAC1 was activated by MsSND1, MsSCM2 and MsSCM4 (Fig. 4b). The two MYB factors caused stronger activation than MsSND1, the highest induction (about 20-fold) being observed for MsSCM4. As reported earlier in Arabidopsis, AtMYB58 and AtMYB63 (homologs MsSCM4) act as direct transcriptional activators of lignin biosynthesis genes and are downstream targets of AtSND1 [30]. The current results suggest that MSLAC1 may be a target of Miscanthus secondary cell wall-regulatory transcription factors.

Transiently expressed MsLac1 localizes to the cell wall of tobacco epidermal leaf cells

In Arabidopsis, AtLAC4, which contributes to stem lignification [15], was localized in the lignified secondary cell wall [31]. Sub-cellular localization of MsLAC1 was assessed by transient expression in tobacco leaves, using a fusion with a C-terminal $\mathrm{pH}$-stable mCherry-tag [32]; Fig. 5). To distinguish between the plasma membrane and the cell wall, the plasma membrane-localized fusion protein LTI6b-GFP was co-transformed [33]. After plasmolysis, the GFP signal retracted with the cytosol, while MsLAC1-mCherry remained associated with the cell

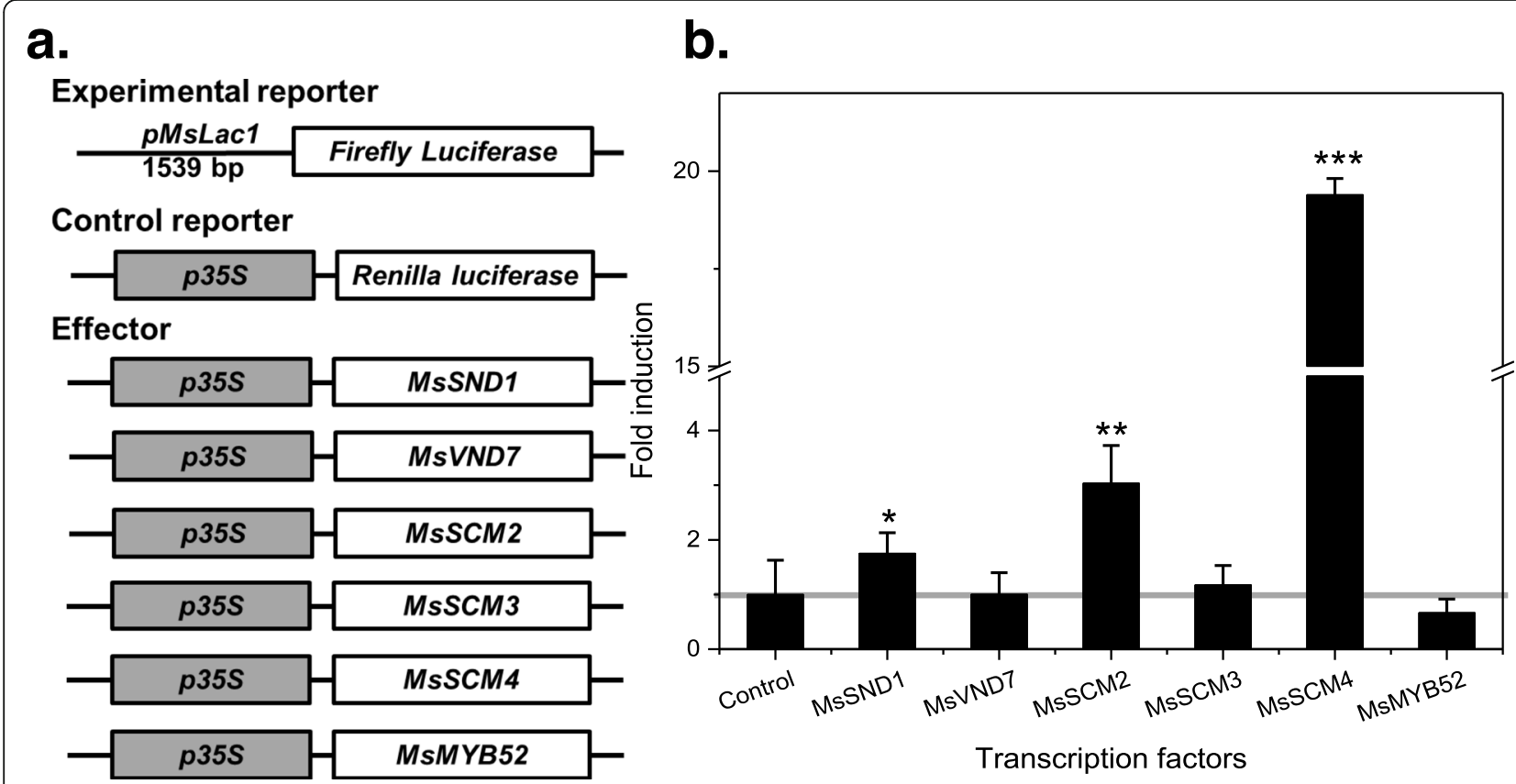

Fig. 4 Activation of MSLAC1 promoter by SND1 and SCM transcription factors from M. sinensis. a Constructs for dual luciferase assay; Renilla luciferase gene fused with 355 promoter was included for normalization. b Activation of MsLAC1 promoter by different transcription factors. Gene constructs were delivered by particle bombardment to grapevine suspension cultured cells as previously described (Golfier et al., 2017); all experiments were repeated at least 3 times, and bars indicate mean \pm SD of three technical replicates from a representative experiment. Student's t-test was used to determine the significant difference of the induction: ${ }^{*}, P<0.05 ;{ }^{*}, P<0.01 ;{ }^{* *}, P<0.001$ 

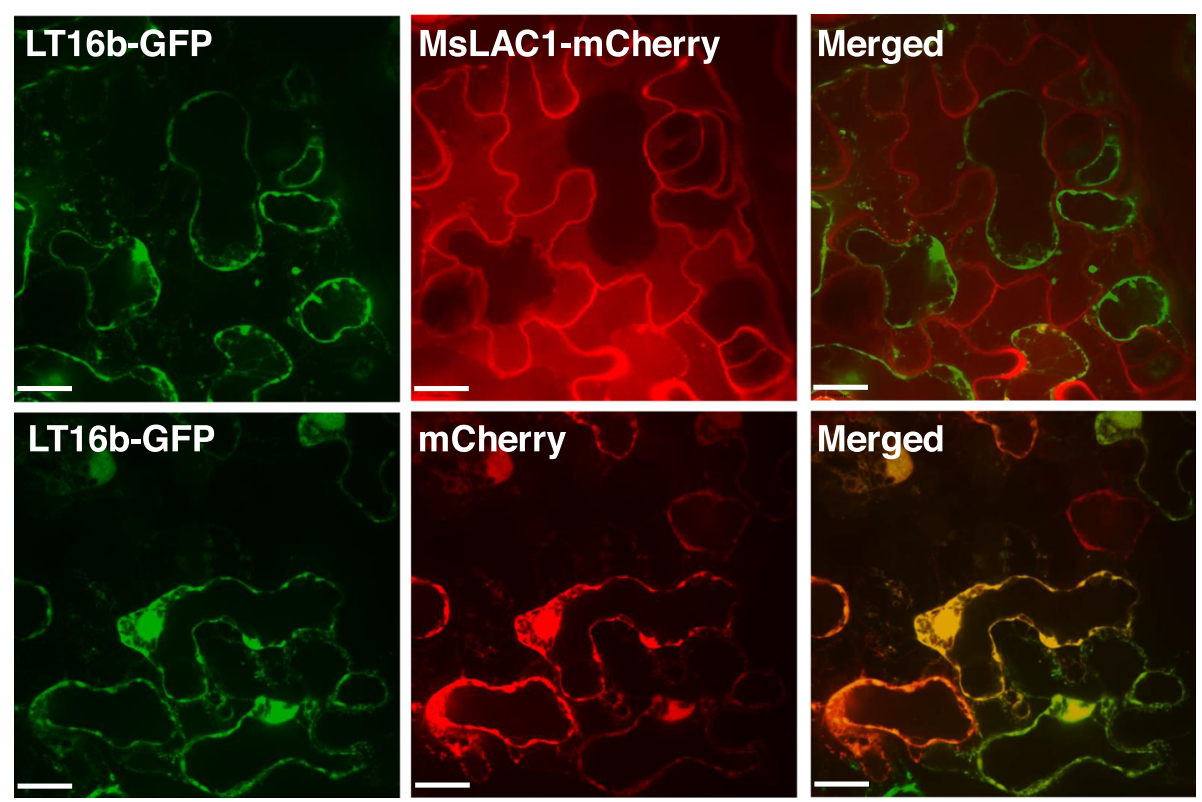

Fig. 5 Localization of MSLAC1 in the cell wall compartment after transient expression in Nicotiana benthamiana leaf. Transient expression of MsLAC1-mCherry and LT16b-GFP (plasma membrane marker fused with GFP) in tobacco epidermal leaf cells after co-infiltration with Agrobacteria harboring the respective constructs. Upper panel shows cell wall association of MsLAC1, whereas the Lti6-GFP-labelled plasma membrane retracts. Lower panel shows a cell co-expressing Lti6b-GFP and a cytosolic mCherry control retracting with the protoplast. All pictures were taken $2 \mathrm{~h}$ after onset of plasmolysis (i.e. incubation in $30 \% \mathrm{w} / \mathrm{v}$ sucrose solution). Scale bars: $16 \mu \mathrm{m}$

walls of the epidermal cells, thus indicating localization of MsLAC1 to the cell wall matrix (Fig. 5).

\section{MsLAC1 oxidizes monolignols in vitro}

To determine the enzymatic activity of MsLAC1, we generated recombinant protein in Pichia pastoris. Zymogram analysis revealed a time-dependent increase of a single activity band, reaching its maximum intensity 8 days after induction expression (Fig. 6a). Western blot analysis using anti-MYC antibody confirmed the increasing concentration of recombinant MsLAC1 protein with a signal at $150 \mathrm{kDa}$ (bottom panel, Fig. 6a). As indicated above, 15 putative $\mathrm{N}$-glycosylation sites were predicted for the MsLAC1 protein sequence. Thus, the conspicuous difference between the calculated molecular mass for the MsLAC1 protein sequence $(63 \mathrm{kDa})$ and the produced recombinant MsLAC1 $(150 \mathrm{kDa})$ is likely due to $\mathrm{N}$ glycosylation and, possibly, additional O-glycosylation or other post-translational modifications [24, 34, 35].

To understand the catalytic property of the recombinant MsLAC1, the oxidation of different monolignols were measured by determining the decrease of different substrates. While recombinant MsLAC1 enzyme was able to oxidize all supplemented monolignols, sinapyl alcohol was oxidized with the highest efficiency (Fig. 6). In contrast, cinnamyl alcohol was oxidized with the lowest efficiency (Additional file 1: Figure S3). Apparently, the efficiency of recombinant MsLAC1 enzyme was connected to the presence of methoxy substituents on the various substrates. Previous studies have also shown that a methoxy substituent in the ortho-position relative to the phenolic $\mathrm{OH}$-group can enhance the polymerization rate by laccases [36]. These results suggest that the recombinant MsLAC1 is likely capable of oxidizing monolignols to radicals, which undergo cross-coupling spontaneously to form more complex polymers.

\section{Phenotypical complementation and recovery of both lignin content and lignin composition in the Arabidopsis lac4-2 lac17 double mutant by MsLAC1}

To assess whether MsLAC1 is capable of lignin polymerization in planta, several independent homozygous lines expressing $M s L A C 1$ under the control of the AtLAC17 promoter (pAtLAC17::MsLAC1) or a corresponding control construct (dummy) in the lac4-2 lac17 double mutant background were generated, and expression of MsLAC1 was confirmed by qPCR (Fig. 7a). The semi-dwarf phenotype of the lac4-2 lac17 mutants under constant light conditions [15] was fully reversed in two independent lines expressing pAtLAC17::MsLAC1 (Fig. 7b). Furthermore, using $\mathrm{HCl}$-phloroglucinol staining of stem cross sections, complete reversal of the irregular xylem phenotype of the inflorescence stems of the lac4-2 lac17 double mutant was apparent in the lines complemented with $p A t L A C 17:: M s L A C 1$ (Fig. 7c). 


\section{a. Days after induction}
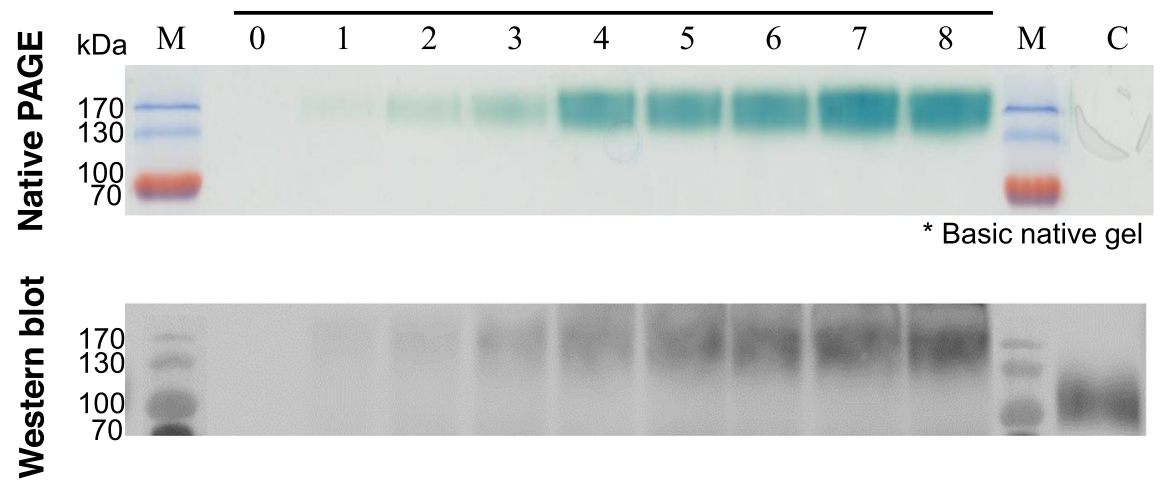

b.

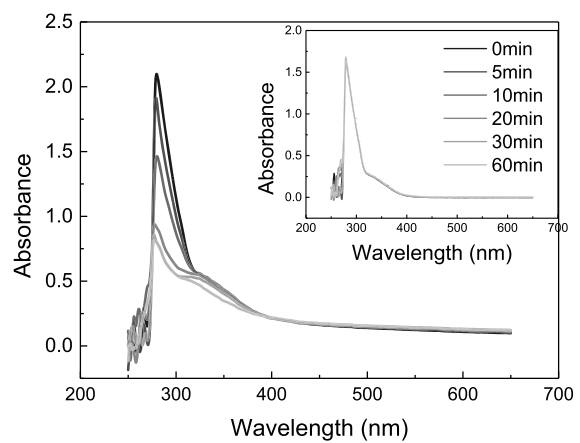

C.

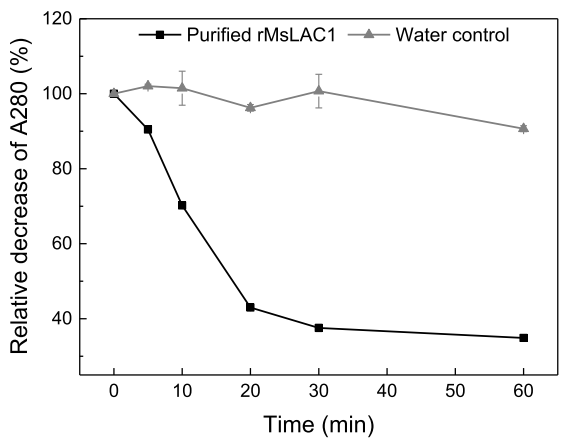

Fig. 6 Expression of recombinant MsLAC1 protein and oxidation of sinapyl alcohol by purified recombinant protein. a The protein was expressed in P. pastoris and analyzed by Native PAGE and Western blot. After methanol induction samples of culture medium were collected at daily intervals, cleared by centrifugation, and $10 \mu$ l of supernatant were filtered and loaded. The zymogram was stained with $10 \mathrm{mM}$ ABTS. Western blot was developed with anti-MYC antibody. M: PageRular Prestained Protein Ladder, 10-170 kDa. C: Crude extract from fermentation broth of $P$. pastoris transformed with pPICZaAfeh, 8 days after induction. Sinapyl alcohol (final concentration $1 \mathrm{mM}$ ) was incubated with $0.002 \mathrm{U}$ recombinant MSLAC1 protein in $50 \mathrm{mM}$ acetate buffer, pH 3.0. b Spectra of reaction mixtures $(250 \mathrm{~nm}-650 \mathrm{~nm}$ ) were recorded at indicated time intervals (the insert indicates the control with substrate only). c Time course of absorption change at $280 \mathrm{~nm}$. The initial absorbance at $280 \mathrm{~nm}$ was set as $100 \%$ individually for the calculation of absorbance decrease with purified protein and water control

To analyze lignin content and composition, dry stems of the lac4-2 lac17 double mutant, MsLAC1complemented plants, and the corresponding controls were subjected to lignin quantification and compositional analyses (Fig. 8a, Tables 1 and 2). As previously reported, the lac4-2 lac17 double mutant has lower lignin content when compared to wild-type plants [15]. Under our growth conditions, total Klason lignin (KL) content of wild-type Col-O plants was $18.3 \%$ (3.4\% acid soluble lignin [ASL] and $14.9 \%$ insoluble lignin [IL]). IL decreased to approximately $9 \%$ in the lac4-2 lac17 double mutant, while ASL remained unchanged. In comparison, the negative control expressing the pAtLAC17::Dummy construct, displayed ASL and IL levels similar to the lac4-2 lac17 double mutant. In the two independent pAtLAC17::MsLAC1 lines, total lignin content was restored to 17.2 and $18.5 \%$, respectively (Fig. 8a).

The Arabidopsis lac4-2 lac17 double mutant also displayed a change in the $\mathrm{S} / \mathrm{G}$ monolignol ratio, increasing from 0.54 (wild type) to 0.80 (double mutant) (Table 1). More specifically, the monolignol composition of lignin in the stem tissue of the lac42 lac17 mutant showed a $25 \%$ reduction in the $\mathrm{S}$ subunits, whereas the amount of $G$ subunits decreased by $57 \%$ (Table 2). The negative controls (transformed with pATLAC17::Dummy) behaved like the double mutant, while complementation with MsLAC1 (pAtLAC17::MsLAC1 lines) partially restored wild type levels of $S$ and $G$ subunits (Tables 1 and 2). In association with the lignin modifications, the observed increase in structural carbohydrates in the lac4-2 lac17 double mutant was also reversed by complementation with MsLAC1 (Fig. 8b). Together, these observations clearly show that by expressing $M s L A C 1$ under control of the AtLAC17 promoter in the lac4-2 lac17 mutant, not only are growth-related phenotypes restored, but also the chemical and morphological attributes of the cell walls are largely restored. 
a.

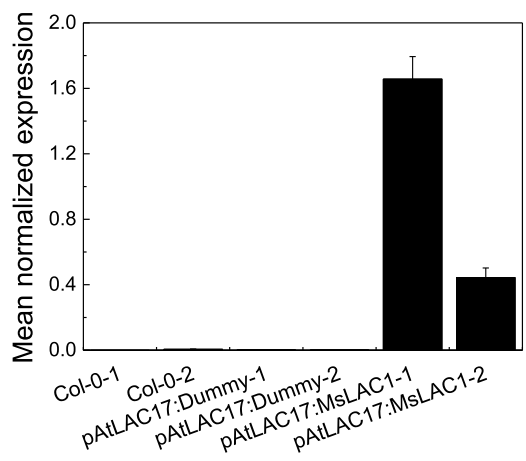

b.

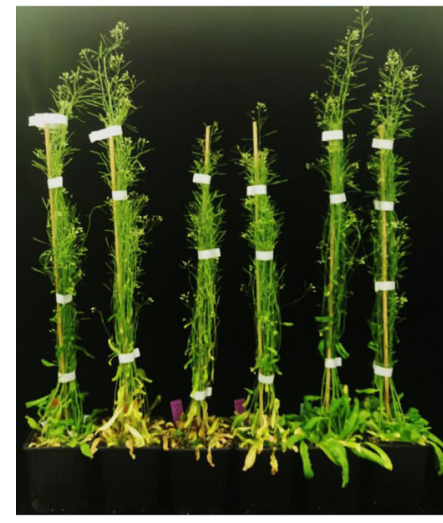

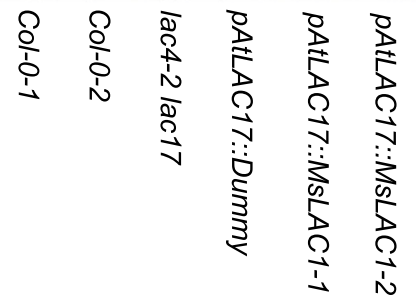

c.

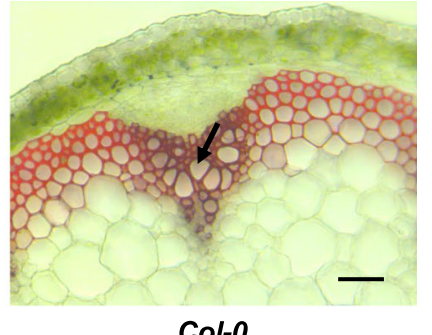

Col-0

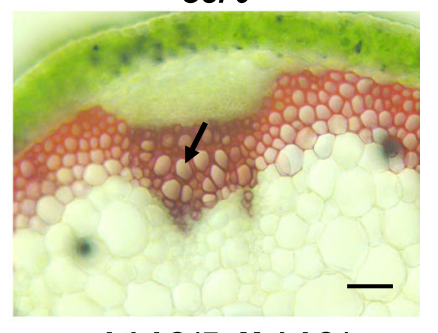

pAtLAC17::MsLAC1

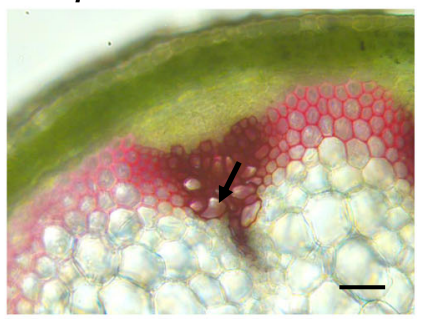

lac4-2 lac17

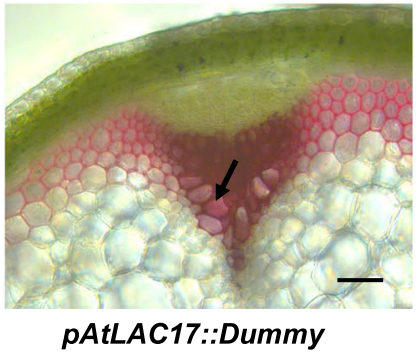

Fig. 7 Complementation of lac4-2 lac17 double mutant with MsLAC1, expressed under control of the AtLAC17 promoter. a Confirmation of MsLAC1 transcript expression in the complemented double mutant by qPCR (AtPDF2 used as reference gene). b Phenotype of Col-O (wild type), double mutant lac4-2 lac17, and PAtLAC17::MsLAC1-complemented double mutant plants grown in growth chamber under constant light $\left(135 \mu \mathrm{mol} / \mathrm{m}^{2} \mathrm{~s}\right)$. c Stem cross-sections stained for lignification with $\mathrm{HCl}$-phloroglucinol. Scale bars: $100 \mu \mathrm{m}$

In Arabidopsis, ectopic expression of MsLAC1 promotes interfascicular fiber development resulting in higher lignin content, lowered S/G ratio and shorter stems Previous work had shown that over-expression of either AtLAC4 or AtLAC17 caused ectopic lignification, even in primary cell walls when exogenous monolignols are externally supplied [37]. To evaluate the effect of ectopic expression of MSLAC1 on growth, Arabidopsis plants expressing MsLAC1 under the control of the CaMV35S promoter were generated in the Col-O background. MsLAC1 transcript levels were determined by qPCR, and two independent lines displaying high expression levels were selected for comparative analyses (Additional file 1: Figure S4).
When plants ectopically expressing MsLAC1 (p35S:: MsLAC1-1 and p35S::MsLAC1-2) were grown under constant light, both lignin content and composition in stem were affected. As shown in Fig. 8a, ASL content remained largely unchanged, but IL content increased from $14.9 \%$ in Col-O to 16.9 and $17.4 \%$ in $35 S:$ : MsLAC1-1 and $p 35 S:: M s L A C 1-2$, respectively (the two negative control lines were unchanged). Notably, the amount of $\mathrm{G}$ subunits was also increased in the p35S::MsLAC1 lines, reducing the $\mathrm{S} / \mathrm{G}$ ratio (Table 2). Conversely, sugar contents (i.e., glucose, xylose, mannose, galactose, rhamnose and arabinose) were not affected by ectopic expression of MsLAC1 (Additional file 1: Figure S5). 

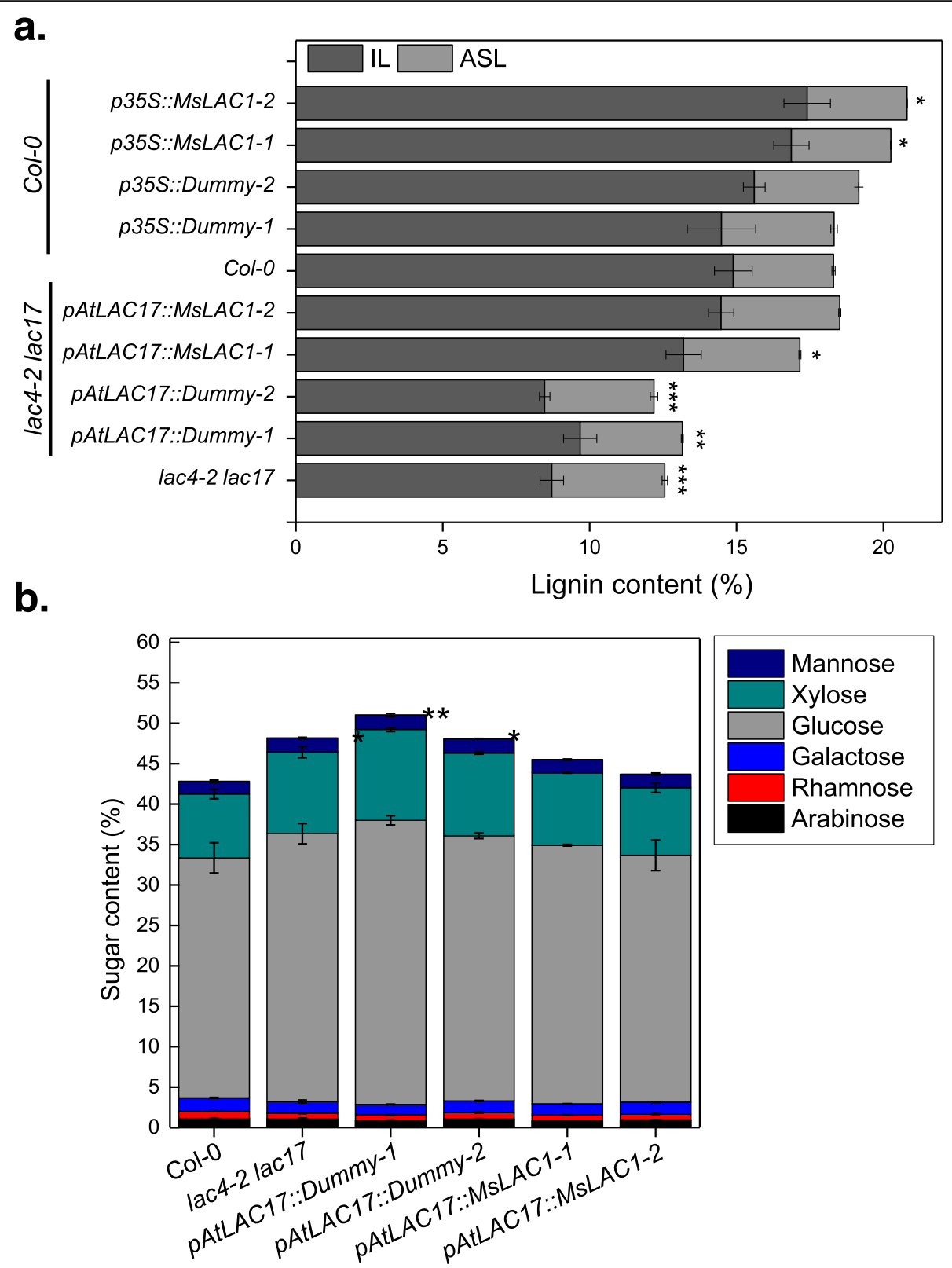

Fig. 8 Lignin (a) and structural sugar contents (b) of mature stems from different Arabidopsis lines. Insoluble lignin (IL) and acid-soluble lignin (ASL) contents (\% weight) were determined in mature stems of wild type, double mutant and complemented double, respectively. Plant materials from 3 to 4 plants were pooled as one replicate. Three replicates were then measured independently. Bars indicate mean \pm SD of the replicates. Student's t-test was used to determine significant differences for total lignin and sugar contents: ${ }^{*}, \mathrm{P}<0.05 ;{ }^{* *}, \mathrm{P}<0.01 ;{ }^{* * *}, \mathrm{P}<0.001$

Plant growth of $p 35 S:: M s L A C 1-1$ and $p 35 S:: M s L A C 1-$ 2 lines under constant light was negatively affected when compared with Col-O wild type and empty vector control lines (Additional file 1: Figure S4). Previous studies have indicated that increased lignification (induced by overexpressing lignin-related TFs or enzymes involved in lignification) can impair plant growth [30, 38]. Thus, we hypothesized that the induced change in lignin content and composition in the p35S::MsLAC1 lines were the cause for the observed shorter inflorescence stems
(Additional file 1: Figure S4). Indeed, in mature $p 35 S:$ : $M s L A C 1$ plants (30 cm from tip), histochemical inspection indicated a $17.4-35.0 \%$ larger lignified xylem area than those for the corresponding controls (Fig. 9), and this is accompanied by an enhancement of interfascicular fiber formation. Specifically, 3-4 layers of interfascicular sclerified cells were observed in the cross-section area of WT and control lines, while plants overexpressing MsLAC1 displayed 4-6 layers (Fig. 10). These results corroborate the predicted function of MsLAC1 in 
Table 1 Relative H, G, and S monomer contents in lignin from different Arabidopsis lines as determined by thioacidolysis

\begin{tabular}{|c|c|c|c|c|}
\hline Arabidopsis lines & $\mathrm{H} \%$ & G\% & $\mathrm{S} \%$ & $\mathrm{~S} / \mathrm{G}$ \\
\hline lac4-2 lac17 & $2.34 \pm 0.51$ & $54.41 \pm 1.39^{\mathrm{a}}$ & $43.24 \pm 1.89^{a}$ & $0.80 \pm 0.06^{a}$ \\
\hline pAtLAC17::Dummy-1 & $2.15 \pm 0.10$ & $54.55 \pm 1.21^{\mathrm{a}}$ & $43.30 \pm 1.24^{\mathrm{a}}$ & $0.79 \pm 0.04^{a}$ \\
\hline pAtLAC17::Dummy-2 & $2.44 \pm 0.30$ & $54.95 \pm 1.38^{a}$ & $42.62 \pm 1.46^{\mathrm{a}}$ & $0.78 \pm 0.05^{a}$ \\
\hline pAtLAC17::MsLAC1-1 & $1.21 \pm 0.05$ & $60.92 \pm 2.04^{c}$ & $37.87 \pm 2.08^{b}$ & $0.62 \pm 0.06^{b}$ \\
\hline pAtLAC17::MsLAC1-2 & $0.94 \pm 0.38$ & $63.39 \pm 0.57^{b c}$ & $35.67 \pm 0.29^{b}$ & $0.56 \pm 0.01^{b}$ \\
\hline Col-O & $1.28 \pm 0.18$ & $64.26 \pm 1.01^{b}$ & $34.46 \pm 1.16^{b}$ & $0.54 \pm 0.03^{b}$ \\
\hline p35s::Dummy-1 & $1.45 \pm 0.45$ & $64.28 \pm 0.68^{b c}$ & $34.27 \pm 1.13^{b}$ & $0.53 \pm 0.02^{b}$ \\
\hline p35s::Dummy-2 & $1.81 \pm 0.26$ & $64.36 \pm 0.22 \mathrm{bc}$ & $33.83 \pm 0.47^{b}$ & $0.53 \pm 0.01^{b}$ \\
\hline p35s::MsLAC1-1 & $1.19 \pm 0.72$ & $70.63 \pm 0.84^{d}$ & $28.18 \pm 0.17^{c}$ & $0.40 \pm 0.01^{c}$ \\
\hline p35s::MsLAC1-2 & $1.77 \pm 0.29$ & $68.52 \pm 0.59^{d}$ & $29.71 \pm 0.32^{c}$ & $0.43 \pm 0.01^{c}$ \\
\hline
\end{tabular}

Percentages for $\mathrm{H}, \mathrm{G}$ and $\mathrm{S}$ monomers, and S/G ratios. All measurements were repeated three times. One-way ANOVA (followed by Tukey test) was used to determine significant differences for $\mathrm{G} \%, \mathrm{~S} \%$ and $\mathrm{S} / \mathrm{G}$ ratios at $P<0.05$. Samples with significant statistic difference are labelled with different letters

lignification and development of interfascicular fibers, which, in turn, represses stem growth (Additional file 1: Figure S4).

\section{Discussion}

Plant laccases $[15,19,20,22,39]$ and peroxidases $[14,31]$ have been identified as key enzymes in lignin biosynthesis, playing a unique role in monolignol polymerization. For several plant species, both monocots and dicots, specific laccase isoforms have been shown to contribute to monolignol polymerization, affecting lignin content and lignin composition. The present study has extended this knowledge to Miscanthus as an important bioeconomy crop, providing not only a comprehensive functional analysis of a specific laccase isoform, MsLAC1, but also unraveling its specific effect on changing lignin composition, i.e., selectively promoting $\mathrm{G}$ unit deposition into lignin in both relative (decreasing $S / G$ ratio) and absolute terms ( $G$ content). In agreement with previous work by Golfier et al. [9] and $\mathrm{Hu}$ et al. [8], our data further support the notion that the molecular network regulating secondary cell wall formation and lignification is largely conserved between dicots and monocots [40].
Characterization of MsLAC1, a Miscanthus laccase isoform The Miscanthus laccase isoform MsLAc1 has been identified as a potential key enzyme for monolignol polymerization based on i) its close sequence relationship with other monocot and dicot laccases known to be involved in lignin biosynthesis (Fig. 1, Additional file 1: Figure S1), ii) its co-expression with several genes of lignin biosynthesis, including genes of cognate transcription factors, in tissues (young stem internodes, leaf growth zones) known to undergo lignification (Figs. 2 and 3), iii) activation of the promoter region of its gene by transcription factors regulating secondary cell wall and lignin biosynthesis (Fig. 4, [9]; the strong induction of the MsLAC1 promoter by MsSCM4, a transcription factor homologous to AtMYB58 and AtMYB63, both known to induce the expression of AtLAC4 in Arabidopsis [30], iv) its targeting to the cell wall compartment (Fig. 5, with mCherry signals detected in cell wall after plasmolysis), and v) its in vitro ability to oxidize monolignols with a preference for sinapyl alcohol (Fig. 7, Additional file 1: Figure S3). In summary, these results suggested a role for MsLAC1 in the lignification process of Miscanthus.

Table 2 Absolute contents of $\mathrm{H}, \mathrm{G}$, and $\mathrm{S}$ monomers in lignin of different Arabidopsis lines

\begin{tabular}{|c|c|c|c|c|c|}
\hline $\begin{array}{l}\text { Arabidopsis } \\
\text { Line }\end{array}$ & H lignin & G lignin & S lignin & Total & Relative yield/\% \\
\hline lac4-2 lac17 & $2.3 \pm 0.9$ & $60.3 \pm 5.6^{a}$ & $47.8 \pm 1.1^{a}$ & $110.4 \pm 7.6^{a}$ & $68.2 \pm 0.2^{a}$ \\
\hline pAtLAC17::Dummy & $1.7 \pm 0.2$ & $59.3 \pm 0.4^{a}$ & $46.0 \pm 2.7^{a}$ & $107.0 \pm 2.6^{a}$ & $66.1 \pm 0.1^{a}$ \\
\hline pAtLAC17::MsLAC1 & $2.3 \pm 0.2$ & $113.5 \pm 6.2^{b}$ & $70.6 \pm 6.4^{b}$ & $186.3 \pm 10.4^{b}$ & $93.4 \pm 0.2^{c}$ \\
\hline Col-O & $1.8 \pm 0.6$ & $149.2 \pm 30.2^{b}$ & $68.9 \pm 8.0^{b}$ & $219.8 \pm 38.6^{b}$ & $100^{b}$ \\
\hline p35s::Dummy & $2.2 \pm 0.2$ & $150.8 \pm 3.5^{b}$ & $58.9 \pm 1.3^{a b}$ & $211.9 \pm 4.8^{b}$ & $105.1 \pm 0.1^{b}$ \\
\hline p35s::MsLAC1 & $3.2 \pm 1.7$ & $192.1 \pm 16.3^{c}$ & $76.6 \pm 5.2^{b}$ & $271.8 \pm 20.2^{c}$ & $111.1 \pm 0.2^{d}$ \\
\hline
\end{tabular}

Yields of $\mathrm{H}, \mathrm{G}$ and $\mathrm{S}$ monomers after thioacidolysis released from extract-free samples (i.e. after acetone extraction) are presented as $\mu$ mol per gram sample. Relative yields are calculated based on total amount of monomer per gram of Klason lignin. Wild type (Col-0) was used as control and its yield arbitrarily set to $100 \%$. All measurements were repeated three times. One-way ANOVA (followed by Tukey test) was used to determine significant differences at $P<0.05$. Samples with significant statistic difference are labelled with different letters 


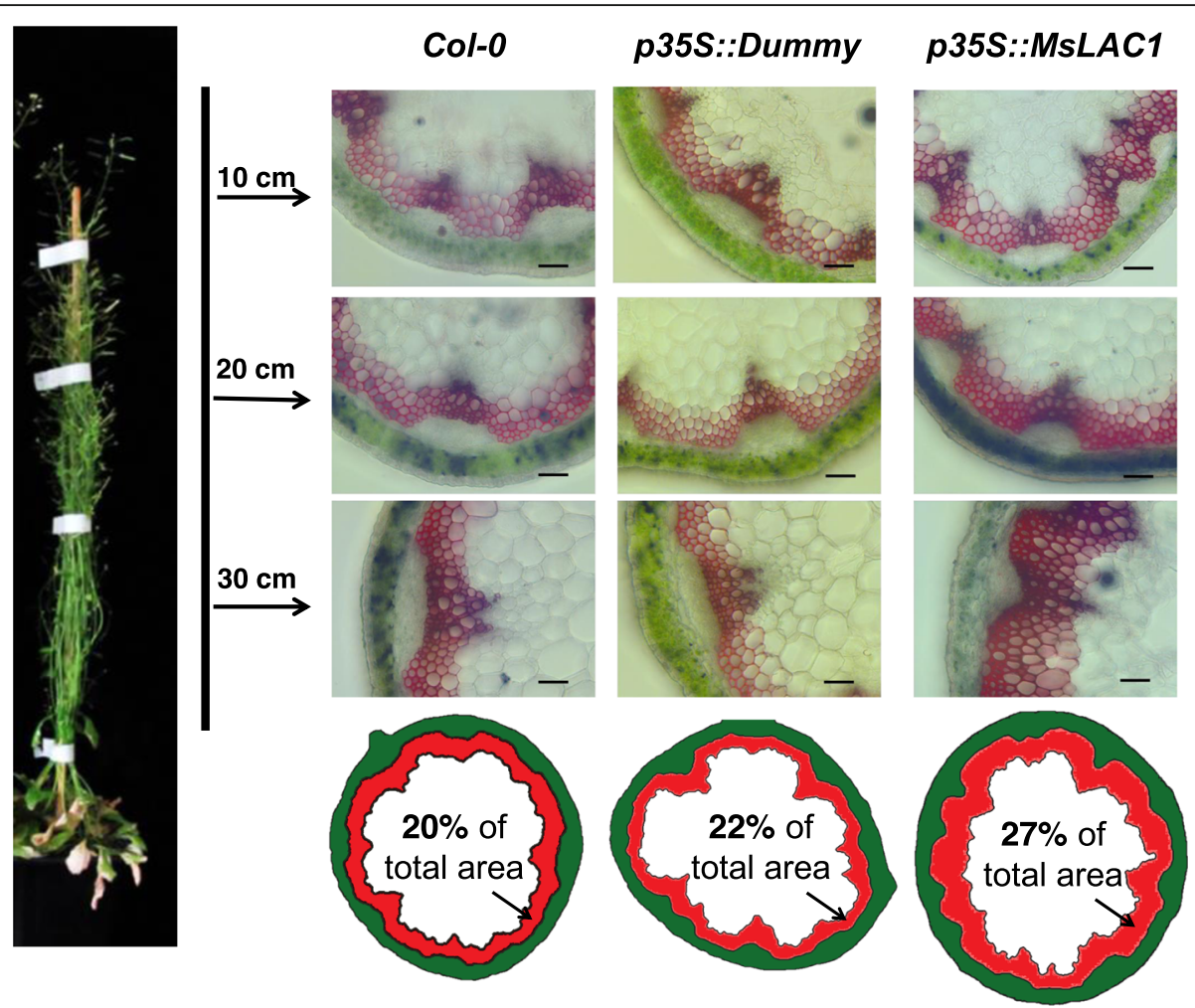

Fig. 9 Increased stem lignification in Arabidopsis Col-0 ectopically expressing MsLAC1 under control of the 35S-promoter (p355::MsLAC1). Plants were cultivated under continuous light $\left(135 \mu \mathrm{mol} / \mathrm{m}^{2} \mathrm{~s}\right)$. Stem cross sections were taken at $10 \mathrm{~cm}, 20 \mathrm{~cm}$ and $30 \mathrm{~cm}$ from tip and were stained with phloroglucinol-HCl. Scale bars: $100 \mu \mathrm{m}$. The imageJ-based diagrammatic representation indicated the area percentage of lignified xylem tissue of the entire cross-section $(30 \mathrm{~cm}$ from tip)

\section{In Arabidopsis, MsLAC1 promotes lignification of interfascicular fibers, selectively promoting deposition of G subunits}

In absence of available Miscanthus laccase mutants, the in vivo function of MsLAC1 was explored in Arabidopsis via complementation of the Arabidopsis lac4-2 lac17 double mutant, which displays a clearly defined irregular xylem phenotype [15]. The rescue of the growth and collapsed xylem vessels phenotypes, together with the restored lignin content and composition in the complemented mutant (Figs. 7 and 8) confirm that MsLAC1 can functionally replace the combined activities of the Arabidopsis laccases AtLAC4 and AtLAC17. Beyond this observation, the conspicuous promotion of interfascicular fiber lignification after ectopically expressing MsLAC1 under control of the 35S-promoter (Figs. 8, 9 and 10, Additional file 1: Figure S4) may suggest that more $G$ subunits were incorporated (Tables 1 and 2) into lignin of interfascicular fibers, enlarging the lignified xylem area (Fig. 9) and spatially extending the number of lignified cell layers (Fig. 10). Likewise, AtLAC17 was previously shown to be involved in the deposition of $\mathrm{G}$ subunits into lignin of interfascicular fibers [15].
In contrast to MsLAC1, a laccase from sugarcane (SofLAC) could only restore lignin content in an Arabidopsis lac17 mutant, but not lignin composition [16]. Since the S/G ratio in the lac17 mutant is restored to normal level in wild type after reintroduction of AtLAC17, it has been hypothesized that this laccase preferentially uses $\mathrm{G}$ units during polymerization [16]. However, MsLAC1, which displays a strong preference for $\mathrm{S}$ units (Fig. 7, Additional file 1: Figure S3), could also reduce the S/G ratio, i.e., from 0.78-0.82 in lac4-2 lac17 mutant to 0.57-0.62 in complementation lines, and even to 0.4 in lines ectopically expressing MsLAC1. These results indicate that substrate availability at the site of lignification may be more important than enzyme affinity for different monolignol substrates. In addition, cross talk with peroxidases may be equally important to monolignol polymerization and may impact on final lignin composition. Interestingly, in Arabidopsis, the lignin polymerizing peroxidase AtPRX64 localized to the middle lamella, whereas AtLAC4 localized throughout the secondary cell wall layers [31], indicative of spatial control mechanisms.

Our results demonstrate that ectopic expression of MsLAC1 in Arabidopsis increases lignin content by 


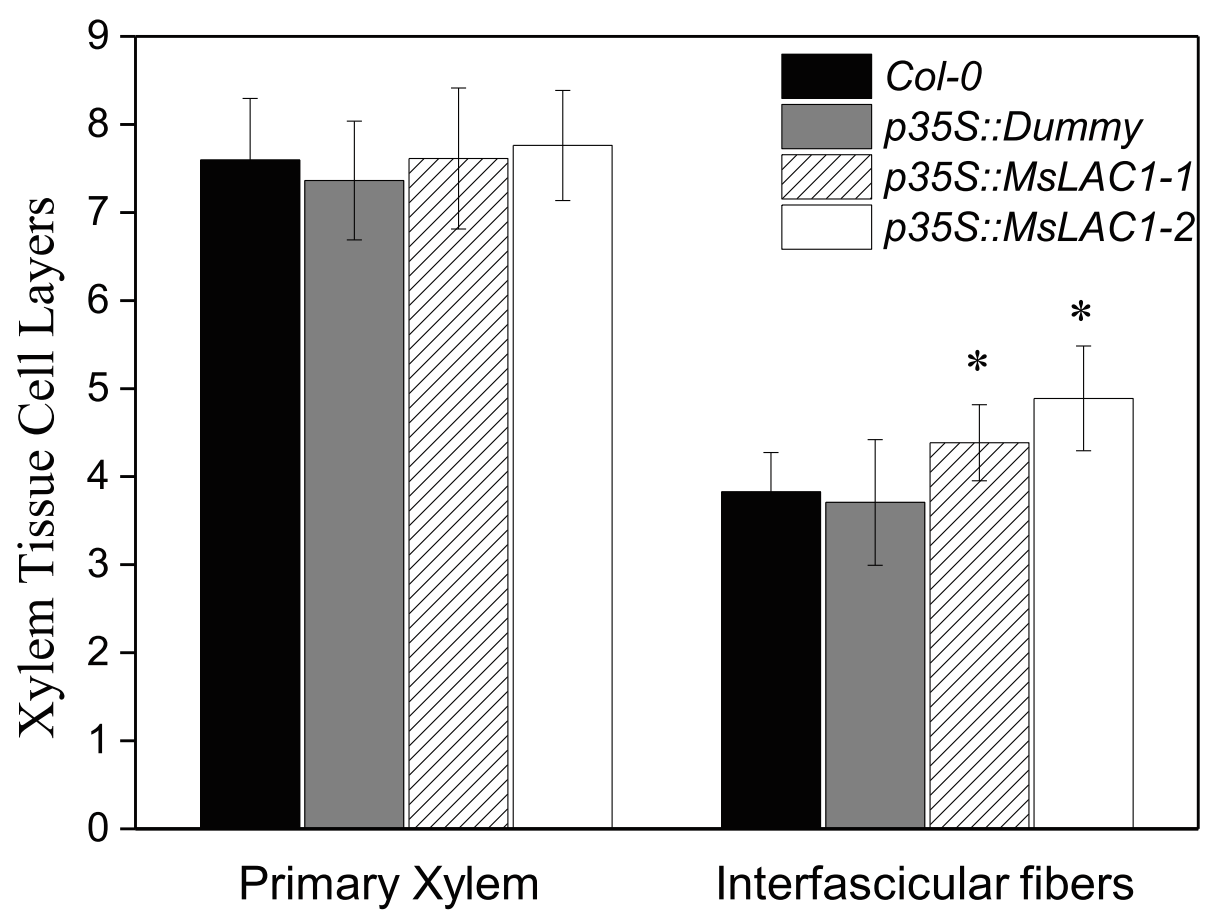

Fig. 10 Quantification of primary xylem and interfascicular lignified cell layers in transgenic Arabidopsis plants. The analysis was based on crosssection of stem (30 cm from tip). Values are means \pm SD for $n=15-20$. Asterisks indicate significant differences $(P<0.05)$ relative to the wildtype determined with a single factor ANOVA

$13.4-16.8 \%$, suggesting that either sufficient endogenous monolignols were available or their biosynthesis was upregulated via feedback loop. Likewise, in poplar stem ectopically expressing a cotton laccase, lignin content was increased by as much as $20 \%$ [41]. Note that since lignin thioacidolysis is based on cleavage of $\beta-\mathrm{O}-4$ bonds, which are predominant in the secondary cell wall [42], the increased relative yield observed for the p35S:: MsLAC1 lines (Table 2) implies that more coniferyl and sinapyl residues were incorporated into lignin.

The increase in G lignin does not result from the enzyme's substrate preference but may be related to substrate availability

Unexpectedly, the in vitro enzyme activity of recombinant MsLAC1 protein (Fig. 7) was highest with sinapyl alcohol, while the complementation and ectopic expression experiments indicated an increased incorporation of $\mathrm{G}$ subunit into lignin, both in relative and absolute terms (Tables 1 and 2). This discrepancy suggests that the impact of MsLAC1 on monolignol polymerization was not simply the result of a preferred affinity towards sinapyl alcohol.

In Arabidopsis, the disruption of LAC4 and/or LAC17 downregulated several monolignol biosynthesis genes [15]. Based on feedback regulation models of biosynthesis and enzyme activity via metabolites, which can also affect the expression of the corresponding genes
[43], accelerated consumption of monomers after overexpression of MsLAC1 may lead to increased biosynthesis of monolignol substrates. Alternatively, cell wall surveillance pathways might affect the expression of cell wall biosynthetic genes.

Considering that Miscanthus has a similar lignin biosynthesis pathway compared with Arabidopsis [8], MsLAC1 may also be involved in the lignification in Miscanthus. Therefore, changing the expression of MsLAC1 in Miscanthus via genetic manipulation may be an attractive strategy to modify the lignin composition while limiting the impact on the total lignin content, which in the end could be used for various end-uses in biorefinery applications [44]. In summary, while the stimulatory effects of MsLAC1 expression on the preferential incorporation of $\mathrm{G}$ subunits and the overall increase in total lignin content were highly significant, the exact molecular mechanisms leading to both phenomena remain to be elucidated.

\section{Conclusions}

The expression of MsLAC1, a Miscanthus laccase isoform gene, is regulated by secondary cell wall MYBs and is involved in lignification of xylem fibers. MsLAC1 complements the lignification-deficient Arabidopsis double mutant lac4-2 lac17. Ectopic expression of MsLAC1 in Arabidopsis promotes interfascicular fiber 
development, resulting in higher lignin content and substantially increased amount of G-lignin, despite a preference for sinapyl alcohol of recombinant MsLAC1 protein in vitro.

\section{Methods \\ Analysis of putative laccase isoforms in a Miscanthus transcriptome}

Using more than 70 laccase protein sequences from both monocot and dicot plants, we performed a local tBLASTn search using the published Miscanthus transcriptome (Barling et al., 2013). More specifically, 17 laccase sequences from Arabidopsis thaliana (The Arabidopsis Information Resource [TAIR]; http://www. arabidopsis.org), 25 laccase sequences from Sorghum bicolor (Phytozome; http://www.phytozome.net/sorghum) and 29 laccase sequences from Brachypodium distachyon (Plant Genome and Systems Biology; http://pgsb. helmholtz-muenchen.de/plant/brachypodium) were used as queries.

Contigs containing full-length protein-coding sequences were further analyzed. Alignment of laccase sequences was performed using ClustalW alignment in MegAlign (DNASTAR, Madison, WI). A phylogenetic tree was generated using the Neighbour-Joining method (http://www.phylogeny.fr/) with bootstrap tests for 1000 replicates. Based on phylogeny and co-expression analyses, MsLAC1 was selected as a putative AtLAC17 ortholog.

To identify the promoter sequences of identified laccases, genomic DNA from Miscanthus sinensis (identification number: Sin-13) was sequenced to generate a partial genome database. The generated contig library was used to search for promoter sequences via BLAST search using the 5 '-terminal sequences of laccases as query, and promoter sequences of corresponding genes were retrieved from the database.

\section{Plant material and growth conditions}

Miscanthus sinensis seeds (identification number: Sin13) were a gift of Iris Lewandowski and are descendant of plants originally collected in Honshu, Japan [45]. Plants were grown in the greenhouse as previously described [9]. For over-expression of MsLAC1 in Arabidopsis Columbia-0 (Col-O) plants and complemented lines of the Arabidopsis lac4-2 lac17 double mutant (gift from Dr. Richard Sibout, Institut Jean-Pierre Bourgin), were grown in soil under short-day conditions $\left(21^{\circ} \mathrm{C}, 8\right.$ $\mathrm{h}$ light $/ 16 \mathrm{~h}$ dark, $110 \mu \mathrm{molm}^{2} \mathrm{~s}$ ) until rosette stage, and then transferred to long-day conditions $\left(21^{\circ} \mathrm{C}, 16 \mathrm{~h}\right.$ light $/ 8 \mathrm{~h}$ dark, $110 \mu \mathrm{mol} / \mathrm{m}^{2} \mathrm{~s}$ ) in the greenhouse. For phenotyping of transgenic Arabidopsis lines, plants were cultivated under continuous light in a growth chamber $\left(21^{\circ} \mathrm{C}, 60 \%\right.$ relative humidity, $135 \mu \mathrm{mol} / \mathrm{m}^{2} \mathrm{~s}$ ).

\section{Histochemical staining of lignin}

Arabidopsis inflorescence stems samples were embedded in $6 \%$ agarose and cut by hand using a razor blade [46]. Lignin was stained with $\mathrm{HCl}$-phloroglucinol staining solution ( $2 \%$ phloroglucinol in absolute ethanol, mixed with equal volume of $\mathrm{HCl}$ before use). O-4-Linked coniferyl and sinapyl aldehydes in lignified cell walls were stained red [47] and images were captured using a Leica DM IRB inverted microscope.

Tissue sampling, RNA extraction and quantitative RT-PCR For 10-day to 3-month-old Miscanthus plants, different tissues (leaf, stem, and root) were separated and collected as a pool. 6-month-old Miscanthus stems and developing leaves were cut and dissected at their nodes, and seven internodes and five leaves were sampled. All samples were immediately frozen in liquid nitrogen.

After grinding, $30 \mathrm{mg}$ or $50 \mathrm{mg}$ of tissue from Miscanthus or Arabidopsis, respectively, were used for RNA extraction as previously described [9]. Subsequently, $0.5 \mu \mathrm{g}$ of total RNA was reverse-transcribed by AMV reverse transcriptase (Roboklon) [48]. Transcript abundance was determined by quantitative RT-PCR using reference genes as described in [9]. Gene-specific primers used for Miscanthus are listed in Additional file 1: Table S2.

\section{Cloning of transcription factors and MsLac1 promoter}

Following the Gateway ${ }^{\oplus}$ cloning protocol (Fisher Scientific), the entry vector pDONR201 was used for initial cloning, and two different destination vectors, pART7 and pLuc, were used as effector and reporter plasmids, respectively, as previously reported [48].

Transcription factors MsSND1 and MsSCM2-4 were previously cloned [9], and used in this study. The promoter of $M S L A C 1$ as well as two additional transcription factors, MsVND7 and MsMYB52, were cloned with gene-specific primers containing gateway overhangs (Additional file 1: Table S1). DNA fragments were cloned into pDONR201 via BP reaction according to the manufacturer's instructions, subsequently sequenced and transferred into the corresponding destination vectors using the LR reaction.

\section{Promoter activation via dual luciferase assay}

To determine activation of the MSLAC1 promoter by transcription factors related to lignin biosynthesis, dual luciferase assays were employed using grapevine (Vitis vinifera) suspension cells, as previously described [48]. As indicated in Fig. 4, all transcription factor ORFs were expressed under control of the CaMV35S promoter in pART7, these plasmids being used as effectors. In the reporter plasmid, firefly luciferase was expressed under control of MsLAC1 promoter (pMsLAC1); thus, the 
intensity of fluorescence indicated promoter induction via the respective transcription factors. Reporter plasmid, effector plasmid (and internal control, see below) were then coated onto gold particles and bombarded into grapevine suspension cells. After a two-day culture in the dark, bombarded cells were ground and fluorescence intensity of firefly and Renilla luciferase (internal control for transformation efficiency) in the isolated supernatants were quantified. The ratio between firefly and Renilla luciferase for each transfection experiment was normalized against the Renilla luciferase plasmid pRluc to represent the relative fold-activation of $p M s L A C 1$ via each transcription factors. All measurements were repeated three times (technical repeats), and all experiments were carried out independently at least twice.

\section{Sub-cellular localization of MsLAC1 protein by transient expression in Nicotiana benthamiana leaves}

To determine the sub-cellular localization of the MsLAC1 protein, Agrobacterium tumefaciens ASE $\left(\mathrm{pSOUP}^{+}\right.$) was transformed using the Greengate expression vectors [49] and subsequently infiltrated into leaves of 4-week-old Nicotiana benthamiana plants for transient expression of fluorescent protein-labelled MsLAC1 protein. Since an N-terminal signal peptide was predicted for the full-length MsLAC1 coding sequence, mCherry was fused to its C-terminus. Lt16b-GFP was used as a plasma membrane marker [33]. Agrobacterium strains containing this marker, mCherry tagged MsLAC1, and the p14 silencing inhibitor plasmid were dispersed in transformation buffer $(10 \mathrm{mM} \mathrm{MgCl}, 10$ $\mathrm{mM}$ MES, $150 \mu \mathrm{M}$ acetosyringone, $\mathrm{pH}$ 5.6) to an $\mathrm{OD}_{600}$ of 0.4, 0.4, and 0.1, respectively, and then mixed at equal volumes. After incubation at room temperature (RT) for $2 \mathrm{~h}$, bacterial mixtures were co-infiltrated into tobacco leaves with a $2 \mathrm{ml}$ sterile needle-less syringe. Dummy gene [49] replacing $M s L A C 1$ was used as a control construct that lacked the MSLAC1 coding sequence. Infiltrated leaves were collected after 3 days. To test whether MsLAC1 localizes to the cell wall, leaf discs were incubated in 30\% sucrose solution for $2 \mathrm{~h}$ before microscopy to plasmolyze cell walls from the plasma membrane. Details regarding the Greengate constructs used in this study are presented in the legend of Fig. 5.

Images were captured using the Perkin-Elmer UltraView VoX spinning disk confocal mounted on a Leica DM16000 inverted microscope with a Hamamatsu 910002 CCD camera. The GFP filter (excitation $488 \mathrm{~nm}$, emission $525 \mathrm{~nm}$ ) was used to image GFP-tagged constructs. The RFP filter (excitation $561 \mathrm{~nm}$, emission 595-625 nm) was used to image mCherry-tagged constructs. Samples were imaged using a Leica oil immersion $20 \times$ or $63 \times$ objective. All images were processed using Volocity image analysis software (Improvision).

\section{Heterologous expression of MsLAC1 protein in Pichia pastoris}

The Pichia pastoris expression vector pPICZ $\alpha$ A containing both MYC and HIS tags was used for heterologous expression of MsLac1 and CiFEH. The purified PCR products of MsLAC1 and the vector pPICZ $\alpha \mathrm{A}$ were digested with EcoRI and $\mathrm{XbaI}$, and then ligated at $4{ }^{\circ} \mathrm{C}$ overnight using T4 DNA ligase (Thermo Fisher Scientific, Catalog number: EL0014). Yeast extract Peptone Dextrose medium (YPD) containing 1\% yeast extract, $2 \%$ peptone and $2 \%$ dextrose was used for general culture. Selected yeast strains were cultivated in buffered complex media containing glycerol (BMGY) and methanol (BMMY) for induction of protein expression. Competent yeast strain X33 cells were prepared fresh, and $2 \mu \mathrm{g}$ of the ligated constructs was used for transformation. Positive colonies were selected on YPD plates containing $50 \mu \mathrm{g} / \mathrm{mL}$ Zeocin ${ }^{\mathrm{ma}}$, followed by colony PCR using the $\alpha$ factor and the 3' AOX1 Sequencing Primers (Additional file 1: Table S1). Colonies were then screened on minimal methanol histidine medium and minimal dextrose histidine medium plates supplemented with Zeocin ${ }^{\text {Tu }}$ for fast methanol utilization (Mut+) phenotype [34].

To check the expression and secretion of recombinant MsLAC1 protein, verified Mut + colonies were cultured in $5 \mathrm{~mL}$ BMGY medium in $50 \mathrm{~mL}$ tubes $\left(30^{\circ} \mathrm{C}, 180 \mathrm{rpm}\right)$ and harvested by centrifugation ( $5000 \mathrm{rpm}, 5 \mathrm{~min}$ ), when cultures had reached an $\mathrm{OD}_{600}$ of 3.0. Pellets were washed and subsequently re-suspended in BMMY medium (supplemented with $0.3 \mathrm{mM} \mathrm{CuSO}_{4}$ ) and diluted to a final $\mathrm{OD}_{600}$ of 1.0 in $30 \mathrm{~mL}$ BMMY media in $300 \mathrm{~mL}$ flasks, cultured at the same conditions $\left(30^{\circ} \mathrm{C}\right.$, $180 \mathrm{rpm}$ ). Methanol (final concentration: 1\%, v/v) was added every day to maintain inducing conditions. After the onset of induction, aliquots were collected daily by centrifugation ( $5000 \mathrm{rpm}, 5 \mathrm{~min})$. Supernatants were dialyzed against pH $5.020 \mathrm{mM}$ sodium acetate buffer overnight at $4{ }^{\circ} \mathrm{C}$ (cold room) and stored for further analysis at $-80^{\circ} \mathrm{C}$. The pPICZ $\alpha$ Afeh strain expressing recombinant fructan exohydrolase (FEH IIa) protein from Cichorium intybus was cultivated under the same conditions and used as a control.

\section{Measurement of laccase activity and protein concentration}

Laccase activity was determined with ABTS (2,2-azinobis3-ethylbenzothiazoline-6-sulfonic acid) as substrate [50]. Sample was diluted in $\mathrm{pH}=5.050 \mathrm{mM} \mathrm{HAc} / \mathrm{NaAc}$ buffer to $180 \mu \mathrm{L}$ and mixed with $20 \mu \mathrm{L}$ ABTS. $180 \mu \mathrm{L}$ buffer without enzyme was mixed with ABTS in the same way and used as control. After incubation in $30{ }^{\circ} \mathrm{C}$ for 3 mins, absorbance at $420 \mathrm{~nm}$ was measured and the increased absorbance comparing with control $(\Delta \mathrm{A})$ was used for the calculation of enzyme activity: 


$$
\text { Laccase activity }\left(\mathrm{U} \cdot \mathrm{L}^{-1}\right)=\frac{V_{t} \times N \times \Delta \mathrm{A} \times 10^{6}}{V_{e} \times \varepsilon \times \Delta \mathrm{T}}
$$

Where, $\mathrm{V}_{\mathrm{t}}$, total volume; $\mathrm{N}$, dilution fold; $\mathrm{V}_{\mathrm{e}}$, sample volume; $\varepsilon$, Molar extinction coefficient for ABTS (3.6× $104 \mathrm{M}-1 \mathrm{~cm}-1) ; \Delta \mathrm{T}$, time of incubation. To select the appropriate wavelength for each substrate, we measured substrate spectra at different concentrations. After calculating the correlation coefficients, we selected the wavelength with the highest absorbance for each substrate: $288 \mathrm{~nm}$ for synalpyl alcohol, P-coumaroyl alcohol, and coniferyl alcohol, as well as $296 \mathrm{~nm}$ for cinnamyl alcohol. One unit of enzyme activity was defined as the amount of enzyme that oxidizes $1 \mu \mathrm{mol}$ substrate per minute at $30^{\circ} \mathrm{C}$. Protein concentration was determined via the Bradford assay using a calibration curve based on bovine serum albumin $(0.1-1 \mathrm{mg} / \mathrm{mL})$ with Bradford Reagent from Sigma (Product number: B6916).

\section{Enzymatic oxidation of monolignols by recombinant MsLAC1 protein}

Cinnamyl alcohol (CAS No.: 104-54-1), p-coumaryl alcohol (CAS No.: 3690-05-9), coniferyl alcohol (CAS No.: 458-35-5), and sinapyl alcohol (CAS No.: 537-33-7) were used as substrates to evaluate the ability of recombinant MsLAC1 protein to oxidize the canonical monolignols. In the assay, $0.02 \mathrm{U}$ enzyme was mixed with 0.5 $\mathrm{mM}$ of each substrates [51]. Reactions were performed in $1.5 \mathrm{~mL}$ reaction vials in $50 \mathrm{mM} \mathrm{NaAc-HAc}$ buffer, $\mathrm{pH} 5.0$, at $30^{\circ} \mathrm{C}$. Absorbance of the reaction mixtures were monitored between 250 to $650 \mathrm{~nm}$ [52]. For sinapyl alcohol, the reaction mixture was scanned at $5,10,20$, 30 and $60 \mathrm{~min}$ after reaction start, respectively, whereas for other monolignols reaction mixtures were scanned at $0.5,1,2,6,12 \mathrm{~h}$, respectively. The reaction was terminated by adding two drops of $10 \mathrm{mM} \mathrm{NaN}_{3}$. Water replacing the recombinant MsLAC1 protein was used as the control in different mixtures and measured in the same time periods.

\section{Native-PAGE, SDS-PAGE and Western blot analysis}

Recombinant protein samples were mixed with Roti ${ }^{\circ}$-Load 1 or Roti-Load 2 followed by incubation at $100^{\circ} \mathrm{C}$ for 5 min, for SDS-PAGE and Native-PAGE, respectively. Both types of electrophoresis were performed on a $4.5 \%$ stacking gel and a $12 \%$ separating gel, using chambers from Bio-Rad ${ }^{\circ}$. Sample loading, running conditions and ABTS staining procedures were as previously described [51].

After SDS-PAGE, proteins were electroblotted onto an Immobilon-P PVDF membrane (Sigma-Aldrich). Recombinant MsLAC1 protein was detected by Western Blot analysis, using anti-MYC (Thermo Fisher Scientific, MA1-980) as a primary antibody, detected by using SuperSignal West Dura Extended Duration Substrate for
HRP (Thermo Fisher Scientific, Catalog number: 34075) after incubation with anti-mouse IgG secondary antibody (Bio-Rad, Catalog number: 172-1011).

\section{Generation of transgenic Arabidopsis lines}

All transgenic plant lines were generated using the Agrobacterium tumefaciens strain ASE $\left(\mathrm{pSOUP}^{+}\right)$ transformed with Greengate constructs using the floral dip method [53]. The Arabidopsis lac4-2 lac17 double mutant was complemented with the pAtLAC17::MsLAC1 construct (i.e., expressing $M s L A C 1$ under control of the AtLAC17 promoter). In addition, MsLAC1 was ectopically expressed in Arabidopsis Col-0 plants, using a p35S::MsLAC1 construct. The Greengate constructs used for over-expression are depicted in Additional file 1: Figure S4. For analysis of complementation and ectopic expression homozygous F3 plants were used.

\section{Lignin analysis}

Mature stems of Arabidopsis were dried and all siliques and leaves removed. Approximately $12 \mathrm{~cm}$ long stem segments were ground and then extracted with hot acetone in a Soxhlet column overnight to remove soluble compounds. The contents of acid soluble lignin (ASL) and insoluble lignin (IL) were measured according to [54]. Neutral cell wall carbohydrate contents were determined via liquid chromatography [55], while lignin composition was determined by gas chromatography after thioacidolysis as previously described [56]. All measurements were done in technical triplicates, using two independent transgenic lines.

\section{Accession numbers}

All sequence data from this paper can be found in GenBank under the following accession numbers. Promoter sequences: $p M s L A C 1$ (MK310212). Coding sequences: MsLAC1 (MK310209), MsSND1 (KY930620), MsVND7 (MK310211), MsSCM2 (MF996502), MsSCM3 (KY930622), MsSCM4 (MF996501), MsMYB52 (MK310210).

\section{Statistical treatment of data}

Three independent experiments were carried out for all measurements. The SD value indicates the standard deviation calculated from the mean. For statistical analysis, the Student's T-test was performed, and asterisks were used to represent the significant differences (", $P<0.05$; ***, $P<0.01$;***, $P<0.001)$. One-way ANOVA followed by Tukey test was also used to determine significant differences for lignin composition. 


\section{Supplementary information}

Supplementary information accompanies this paper at https://doi.org/10. 1186/s12870-019-2174-3.

Additional file 1: Table. S1. Primers used for cloning and colony PCR in this study. Table. S2. Primers used for quantitative real-time PCR analysis. Figure S1. Phylogenetic tree including putative laccases of Miscanthus and laccase proteins from Brachypodium distachyon. Figure S2. Multiple sequence alignment of MsLAC1 with other laccase proteins known to be involved in lignification. Figure S3. Time course of spectral change in reaction mixtures containing cinnamyl, $p$-coumaryl or coniferyl alcohol, respectively, co-incubated with purified rMsLAC1 protein. Figure S4. Under long-day condition, ectopic expression of MsLAC1 (p35S::MsLAC1) in Arabidopsis ecotype Col-0 reduces stem growth. Figure S5. Structural sugar contents in different Arabidopsis lines after ectopic expression of MsLAC1 (p35S:MsLAC1, see Figure S4).

\section{Abbreviations}

ABTS: 2,2-azino-bis3-ethylbenzothiazoline-6-sulfonic acid; ASL: Acid Soluble Lignin; CCOAOMT: Caffeoyl-CoA O-methyltransferase; G: Guaiacyl; H: $p$ Hydroxyphenyl; HCT: Hydroxycinnamoyltransferase; IL: Insoluble Lignin; KL: Klason Lignin; LAC: Laccase; PRX: Peroxidase; S: Syringyl; SCM: Secondary Cell wall MYB protein; SMRE: Secondary wall MYB Responsive Element; SNBE: Secondary cell wall NAC Binding Element; SND1: Secondary wallassociated NAC Domain protein 1; VND7: Vascular-related NAC-Domain protein 7

\section{Acknowledgements}

We thank Sebastian Sorge for help with confocal microscopy, Qi Gao for help with data analysis, UBC Bioimaging Facility for technical support, Ute Kusch and Anja Bausewein for donation of the Pichia FEH strain, Richard Sibout for providing Arabidopsis mutant seeds, and Iris Lewandowski for providing Miscanthus seeds.

\section{Authors' contributions}

FH performed the experimental work; PG, JD and WZ contributed to the cloning of transcription factors; $\mathrm{NH}$ performed part of the confocal microscopy; FU contributed to the measuring of lignin content and composition; KMN, LS and SM contributed to the manuscript preparation; FH, SW and TR co-designed the research plan. All authors have read and approved the manuscript.

\section{Funding}

This work was supported by a grant from the Ministry of Science, Research and the Arts of Baden-Württemberg (FKZ: 7533-10-5-74) to Thomas Rausch and Sebastian Wolf. Research in the laboratory of Sebastian Wolf was supported by the German Research Foundation (DFG) through the Emmy Noether Programme (WO 1660/2). Feng He and Wan Zhang were supported by the Chinese Scholarship Council (CSC) and the Baden-Württemberg bioeconomy graduate program BBW ForWerts (funded by the Ministry of Science, Research and the Arts of Baden-Württemberg). The funders had no role in the design of the study and collection, analysis, and interpretation of data and in writing the manuscript.

\section{Availability of data and materials}

All data generated or analyzed during the study are included in this manuscript and Additional file.

\section{Ethics approval and consent to participate}

Not applicable.

\section{Consent for publication}

Not applicable.

\section{Competing interests}

The authors declare that they have no competing interests.

\section{Author details}

${ }^{1}$ Centre for Organismal Studies (COS) Heidelberg, Heidelberg University, Heidelberg, Germany. ${ }^{2}$ Department of Wood Science, University of British
Columbia, Vancouver, Canada. ${ }^{3}$ Department of Botany, University of British Columbia, Vancouver, Canada.

Received: 11 July 2019 Accepted: 28 November 2019

Published online: 12 December 2019

\section{References}

1. Lewandowski I, Clifton-Brown JC, Scurlock J, Huisman W. Miscanthus: European experience with a novel energy crop. Biomass Bioenergy. 2000: 19(4):209-27.

2. Brosse N, Dufour A, Meng X, Sun Q, Ragauskas A. Miscanthus: a fastgrowing crop for biofuels and chemicals production. Biofuels Bioprod Biorefin. 2012;6(5):580-98.

3. Adams J, Winters AL, Hodgson EM, Gallagher JA. What cell wall components are the best indicators for Miscanthus digestibility and conversion to ethanol following variable pretreatments? Biotechnol Biofuels. 2018;11(1):67.

4. Lygin AV, Upton J, Dohleman FG, Juvik J, Zabotina OA, Widholm JM, Lozovaya W. Composition of cell wall phenolics and polysaccharides of the potential bioenergy crop-Miscanthus. GCB Bioenergy. 2011;3(4):333-45.

5. Barros J, Serrani-Yarce JC, Chen F, Baxter D, Venables BJ, Dixon RA. Role of bifunctional ammonia-lyase in grass cell wall biosynthesis. Nat Plants. 2016; 2:16050.

6. Vanholme R, Storme V, Vanholme B, Sundin L, Christensen JH, Goeminne G, Halpin C, Rohde A, Morreel K, Boerjan W. A systems biology view of responses to lignin biosynthesis perturbations in Arabidopsis. Plant Cell. 2012;24(9):3506-29.

7. Barling A, Swaminathan K, Mitros T, James BT, Morris J, Ngamboma O, Hall MC, Kirkpatrick J, Alabady M, Spence AK. A detailed gene expression study of the Miscanthus genus reveals changes in the transcriptome associated with the rejuvenation of spring rhizomes. BMC Genomics. 2013;14(1):864.

8. Hu R, Xu Y, Yu C, He K, Tang Q, Jia C, He G, Wang X, Kong Y, Zhou G. Transcriptome analysis of genes involved in secondary cell wall biosynthesis in developing internodes of Miscanthus lutarioriparius. Sci Rep UK. 2017;7(1): 9034

9. Golfier P, Volkert C, He F, Rausch T, Wolf S. Regulation of secondary cell wall biosynthesis by a NAC transcription factor from Miscanthus. Plant Direct. 2017;1(5):e00024.

10. Zhong $R$, Ye Z. Transcriptional regulation of lignin biosynthesis. Plant Signal Behav. 2009;4(11):1028-34.

11. Li P, Ponnala L, Gandotra N, Wang L, Si Y, Tausta SL, Kebrom TH, Provart N, Patel R, Myers CR. The developmental dynamics of the maize leaf transcriptome. Nat Genet. 2010;42(12):1060.

12. Zhong R, Lee C, McCarthy RL, Reeves CK, Jones EG, Ye Z. Transcriptional activation of secondary wall biosynthesis by rice and maize NAC and MYB transcription factors. Plant Cell Physiol. 2011;52(10):1856-71.

13. Valdivia ER, Herrera MT, Gianzo C, Fidalgo J, Revilla G, Zarra I, Sampedro J. Regulation of secondary wall synthesis and cell death by NAC transcription factors in the monocot Brachypodium distachyon. J Exp Bot. 2013;64(5): 1333-43.

14. Shigeto J, Tsutsumi Y. Diverse functions and reactions of class III peroxidases. New Phytol. 2016;209(4):1395-402.

15. Berthet $S$, Demont-Caulet N, Pollet B, Bidzinski P, Cézard L, Le Bris P, Borrega $\mathrm{N}$, Hervé J, Blondet E, Balzergue S. Disruption of LACCASE4 and 17 results in tissue-specific alterations to lignification of Arabidopsis thaliana stems. Plant Cell. 2011;23(3):1124-37.

16. Cesarino I, Araújo P, Mayer JLS, Vicentini R, Berthet S, Demedts B, Vanholme B, Boerjan W, Mazzafera P. Expression of SofLAC, a new laccase in sugarcane, restores lignin content but not S: G ratio of Arabidopsis lac17 mutant. J Exp Bot. 2013;64(6):1769-81.

17. Bryan AC, Jawdy S, Gunter L, Gjersing E, Sykes R, Hinchee MA, Winkeler KA, Collins CM, Engle N, Tschaplinski TJ. Knockdown of a laccase in Populus deltoides confers altered cell wall chemistry and increased sugar release. Plant Biotechnol J. 2016;14(10):2010-20

18. Cho HY, Lee C, Hwang S, Park YC, Lim HL, Jang CS. Overexpression of the OsChl1 gene, encoding a putative laccase precursor, increases tolerance to drought and salinity stress in transgenic Arabidopsis. Gene. 2014;552(1):98105.

19. Zhao Q, Nakashima J, Chen F, Yin Y, Fu C, Yun J, Shao H, Wang X, Wang Z, Dixon RA. Laccase is necessary and nonredundant with peroxidase for 
lignin polymerization during vascular development in Arabidopsis. Plant Cell. 2013;25(10):3976-87.

20. Liang M, Davis E, Gardner D, Cai X, Wu Y. Involvement of AtLAC15 in lignin synthesis in seeds and in root elongation of Arabidopsis. Planta. 2006;224(5): 1185-96.

21. Turlapati PV, Kim K, Davin LB, Lewis NG. The laccase multigene family in Arabidopsis thaliana: towards addressing the mystery of their gene function (s). Planta. 2011;233(3):439-70.

22. Wang Y, Bouchabke-Coussa O, Lebris P, Antelme S, Soulhat C, Gineau E, Dalmais M, Bendahmane A, Morin H, Mouille G. LACCASE5 is required for lignification of the Brachypodium distachyon culm. Plant Physiol. 2015; 168(1):192-204.

23. Wang J, Feng J, Jia W, Chang S, Li S, Li Y. Lignin engineering through laccase modification: a promising field for energy plant improvement. Biotechnol Biofuels. 2015:8(1):1.

24. Coll PM, Tabernero C, Santamaría R, Pérez P. Characterization and structural analysis of the laccase I gene from the newly isolated ligninolytic basidiomycete PM1 (CECT 2971). Appl Environ Microb. 1993;59(12):4129-35.

25. Wang G, Balint-Kurti P. Maize homologs of CCOAOMT and HCT, two key enzymes in lignin biosynthesis, form complexes with the NLR Rp1 protein to modulate the defense response. Plant Physiol. 2016;171(3):2166-77.

26. Cartharius K, Frech K, Grote K, Klocke B, Haltmeier M, Klingenhoff A, Frisch M, Bayerlein M, Werner T. MatInspector and beyond: promoter analysis based on transcription factor binding sites. Bioinformatics. 2005; 21(13):2933-42

27. Zhong R, Yuan Y, Spiekerman JJ, Guley JT, Egbosiuba JC, Ye Z. Functional characterization of NAC and MYB transcription factors involved in regulation of biomass production in Switchgrass (Panicum virgatum). PLoS One. 2015; 10(8):e134611.

28. Zhao Q, Dixon RA. Transcriptional networks for lignin biosynthesis: more complex than we thought? Trends Plant Sci. 2011;16(4):227-33.

29. Zhong R, Ye Z. Complexity of the transcriptional network controlling secondary wall biosynthesis. Plant Sci. 2014;229:193-207.

30. Zhou J, Lee C, Zhong R, Ye Z. MYB58 and MYB63 are transcriptional activators of the lignin biosynthetic pathway during secondary cell wall formation in Arabidopsis. Plant Cell. 2009:21(1):248-66.

31. Yi Chou E, Schuetz M, Hoffmann N, Watanabe Y, Sibout R, Samuels AL. Distribution, Mobility and Anchoring of Lignin-Related Oxidative Enzymes in Arabidopsis Secondary Cell Walls. J Exp Bot. 2018;69(8):1849-59.

32. Sparkes IA, Runions J, Kearns A, Hawes C. Rapid, transient expression of fluorescent fusion proteins in tobacco plants and generation of stably transformed plants. Nat Protoc. 2006;1 (4):2019.

33. Cutler SR, Ehrhardt DW, Griffitts JS, Somerville CR. Random GFP:: cDNA fusions enable visualization of subcellular structures in cells of Arabidopsis at a high frequency. Proc Natl Acad Sci. 2000;97(7):3718-23.

34. Bronikowski A, Hagedoorn P, Koschorreck K, Urlacher VB. Expression of a new laccase from Moniliophthora roreri at high levels in Pichia pastoris and its potential application in micropollutant degradation. AMB Express. 2017;7(1):73.

35. Campos PA, Levin LN, Wirth SA. Heterologous production, characterization and dye decolorization ability of a novel thermostable laccase isoenzyme from Trametes trogii BAFC 463. Process Biochem. 2016;51(7):895-903.

36. Ramalingam B, Sana B, Seayad J, Ghadessy FJ, Sullivan MB. Towards understanding of laccase-catalysed oxidative oligomerisation of dimeric lignin model compounds. RSC Adv. 2017;7(20):11951-8.

37. Schuetz M, Benske A, Smith RA, Watanabe Y, Tobimatsu Y, Ralph J, Demura $\mathrm{T}$, Ellis B, Samuels AL. Laccases direct lignification in the discrete secondary cell wall domains of protoxylem. Plant Physiol. 2014;166(2):798-807.

38. Zhang W, Wei R, Chen S, Jiang J, Li H, Huang H, Yang G, Wang S, Wei H, Liu G. Functional characterization of CCR in birch (Betula platyphyllax Betula pendula) through overexpression and suppression analysis. Physiol Plantarum. 2015;154(2):283-96.

39. Cai X, Davis EJ, Ballif J, Liang M, Bushman E, Haroldsen V, Torabinejad J, Wu $Y$. Mutant identification and characterization of the laccase gene family in Arabidopsis. J Exp Bot. 2006:57(11):2563-9.

40. Rao X, Dixon RA. Current models for transcriptional regulation of secondary Cell Wall biosynthesis in grasses. Front Plant Sci. 2018;9:399.

41. Wang J, Wang C, Zhu M, Yu Y, Zhang Y, Wei Z. Generation and characterization of transgenic poplar plants overexpressing a cotton laccase gene. Plant Cell Tissue Organ Culture. 2008;93(3):303.

42. Russell WR, Forrester AR, Chesson A, Burkitt MJ. Oxidative coupling during lignin polymerization is determined by unpaired electron delocalization within parent phenylpropanoid radicals. Arch Biochem Biophys. 1996;332(2): $357-66$.

43. van der Knaap JA, Verrijzer CP. Undercover: gene control by metabolites and metabolic enzymes. Gene Dev. 2016:30(21):2345-69.

44. Vanholme R, Morreel K, Darrah C, Oyarce P, Grabber JH, Ralph J, Boerjan W. Metabolic engineering of novel lignin in biomass crops. New Phytol. 2012; 196(4):978-1000

45. Clifton-Brown JC, Lewandowski I. Screening Miscanthus genotypes in field trials to optimise biomass yield and quality in southern Germany. Eur J Agron. 2002;16(2):97-110.

46. Mitra PP, Loqué D. Histochemical staining of Arabidopsis thaliana secondary cell wall elements. J Visual Exp JoVE. 2014;87. https://doi.org/10.3791/51381,

47. Pomar F, Merino F, Barceló AR. O-4-linked coniferyl and sinapyl aldehydes in lignifying cell walls are the main targets of the Wiesner (phloroglucinol-HCl) reaction. Protoplasma. 2002;220(1-2):17-28.

48. Wei H, Bausewein A, Greiner S, Dauchot N, Harms K, Rausch T. Ci MYB 17, a stress-induced chicory R2R3-MYB transcription factor, activates promoters of genes involved in fructan synthesis and degradation. New Phytol. 2017; 215(1):281-98.

49. Lampropoulos A, Sutikovic Z, Wenzl C, Maegele I, Lohmann JU, Forner J. GreenGate-A novel, versatile, and efficient cloning system for plant transgenesis. PLoS One. 2013:8(12):e83043.

50. Ng I, Zhang X, Zhang Y, Lu Y. Molecular cloning and heterologous expression of laccase from Aeromonas hydrophila NIU01 in Escherichia coli with parameters optimization in production. Appl Biochem Biotech. 2013; 169(7):2223-35.

51. He F, Qin X, Zhang H, Yang Y, Zhang X, Yang Y. Characterization of laccase isoenzymes from the white-rot fungus Ganoderma sp. En3 and synergistic action of isoenzymes for dye decolorization. J Chem Technol Biot. 2015. 90(12):2265-79.

52. Sterjiades R, Dean JF, Eriksson KL. Laccase from sycamore maple (Acer pseudoplatanus) polymerizes monolignols. Plant Physiol. 1992;99(3):1162-8.

53. Clough SJ, Bent AF. Floral dip: a simplified method for agrobacteriummediated transformation of Arabidopsis thaliana. Plant J. 1998;16(6):735-43.

54. Cullis IF, Saddler JN, Mansfield SD. Effect of initial moisture content and chip size on the bioconversion efficiency of softwood lignocellulosics. Biotechnol Bioeng. 2004:85(4):413-21.

55. Huntley SK, Ellis D, Gilbert M, Chapple C, Mansfield SD. Significant increases in pulping efficiency in $\mathrm{C} 4 \mathrm{H}$-F5H-transformed poplars: improved chemical savings and reduced environmental toxins. J Agr Food Chem. 2003;51 (21): 6178-83.

56. Robinson AR, Mansfield SD. Rapid analysis of poplar lignin monomer composition by a streamlined thioacidolysis procedure and near-infrared reflectance-based prediction modeling. Plant J. 2009:58(4):706-14.

\section{Publisher's Note}

Springer Nature remains neutral with regard to jurisdictional claims in published maps and institutional affiliations.
Ready to submit your research? Choose BMC and benefit from:

- fast, convenient online submission

- thorough peer review by experienced researchers in your field

- rapid publication on acceptance

- support for research data, including large and complex data types

- gold Open Access which fosters wider collaboration and increased citations

- maximum visibility for your research: over $100 \mathrm{M}$ website views per year

At $\mathrm{BMC}$, research is always in progress.

Learn more biomedcentral.com/submissions 